\title{
Cont-930.515.5--3-Revil
}

UCRL-JC-112646 Rev 1

PREPRINT

\section{Emission From Ferroelectric Cathodes}

\author{
S.E. Sampayan, G.J. Caporaso, C.L. Holme:, E.J. Lauer, D. Prosnitz, \\ D.O. Trimble, and G.A. Westenskow
}

This paper was prepared for submittal to

High Intensity Electron Sources, Legnaro, Padova (Italy) May 24-28, 1993

May, 1993

This is a preprint of a paper intended for publication in a joumal or proceedings. Since changes may be made before publication, this preprint is made available with the understanding that it will not be cited or reproduced without the permission of the author.

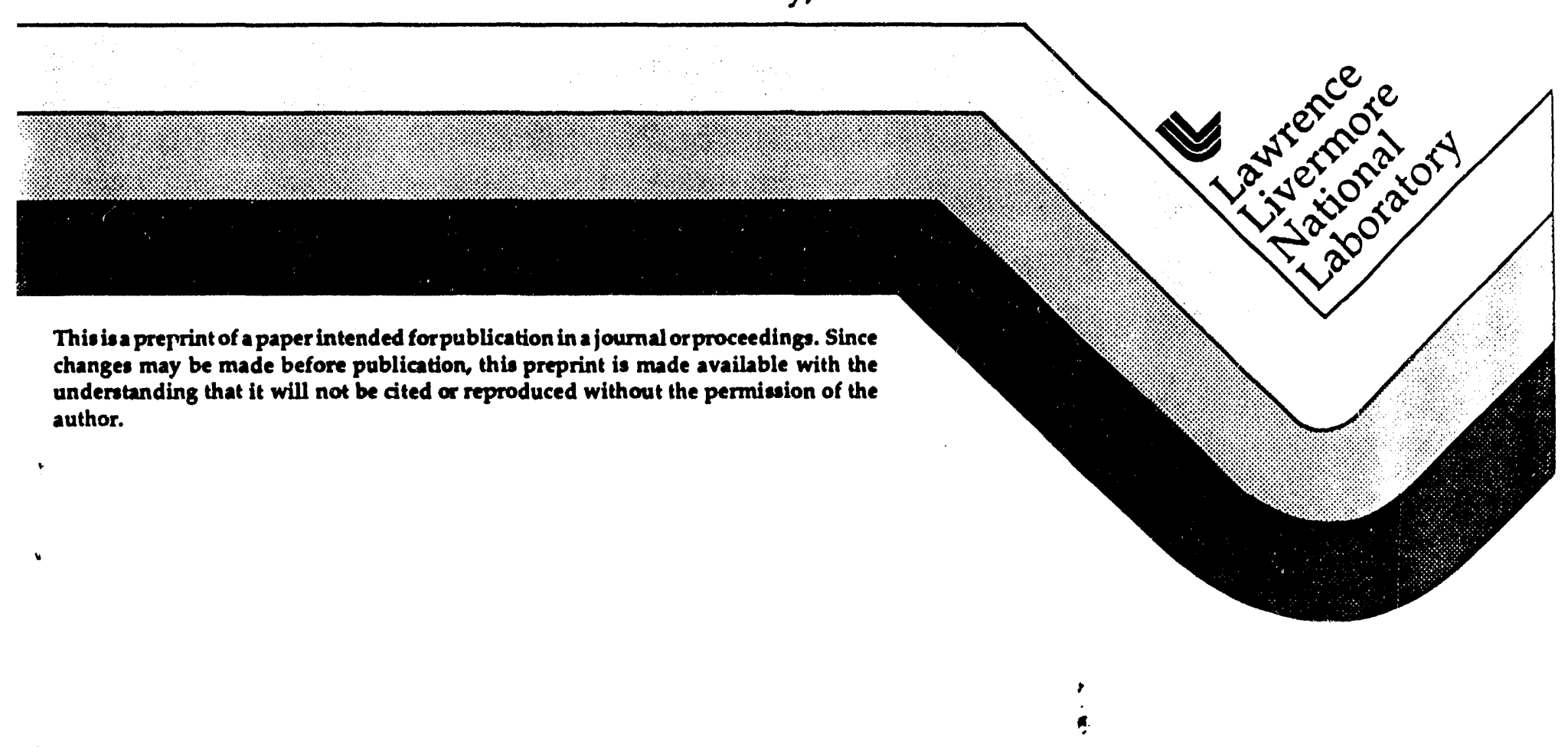




\section{DISCLAIMER}

This document was prepared as an sccount of work sponsored by an agency of the L nited States Government. Veither the L nited States Covernment nor the I niversiry of Califomia nor any of their employees. makes any warrant. express or implied. or assumes any lezal liability or responsibility for the accuracy. completeness. or usefulness of any information. apparafus. product, or process disclosed. of represents that its use would not infringe privatety on ned rights. Reference herein 10 any specific commercial products, process, or service by irade name. Irademark, manufacturer, or otherwise. does not necessarily constitute or imply its endorseraent. recommendation, of favoring by the I nited States Government of the I niversity of Califomia. The views and opinions of authors expressed herein do not necessarily stale or reflect those of the I nited States Governmem thereof, and shall not be used for advertising or product endorsement purposes. 
EMIBSION FROM FERROELECTRIC CATHODEB

S. E. Sampayan, G. J. Caporaso, C. L. Holmes, E. J. Lauer, D. Prosnitz, D. O. Trimble, and G. A. Westenskow University of California

Lawrence Livermore National Laboratory

Livermore, CA 94551

U. S. A

\begin{abstract}
We have recently initiated an investigation of electron emission from ferroelectric cathodes. Our experimental apparatus consisted of an electron diode and a $250 \mathrm{kV}$, $12 \mathrm{ohm}, 70 \mathrm{~ns}$ pulsed high voltage power source. A planar triode modulator driven by a synthesized waveform generator initiates the polarization inversion and allows inversion pulse tailoring. The pulsed high voltage power source is capable of delivering two high voltage pulses within $50 \mu$ s of each other and is capable of operating at a sustained repetition rate of $5 \mathrm{~Hz}$. Our initial measurements indicate that emission current densities above the Child-Langmuir space Charge Limit, $\mathrm{J}_{C L}$, are possible. We explain this effect to be based on a non-zero initial energy of the emitted electrons. We also determined that this effect is strongly coupled to relative timing between the inversion pulse and application of the main anode-cathode pulse. We


also have initiated brightness measurements of the emitted beam and estimate a preliminary lower bound to be on the order of $10^{9} \mathrm{~A} / \mathrm{m}^{2}-\mathrm{rad}^{2}$ for currents close to $\mathrm{J}_{\mathrm{CL}}$ and factor of two less at currents over $4 \mathrm{~J}_{\mathrm{CL}}$. As in our previous measurements at this Laboratory, we performed the measurement using a pepper pot technique. Beamlet profiles are recorded with a fast phosphor and gated cameras. We describe our apparatus and preliminary measurements.

This work was performed under the auspices of the $U$. $S$. Department of Energy by Lawrence Livermore National Laboratory under contract no. W-7405-Eng-48. 
1. Introduction

New research into fast-switching, ferroelectric emitters promises to dramatically influence the state-of-theart in pulsed electron device technology. This new class of electron emitter technology has shown extremely high current densities (of order $1 \mathrm{kA}-\mathrm{cm}^{-2}$ ) and high brightness $\left(10^{10} A-m^{2}-\operatorname{rad}^{2}\right) \quad[1,2]$. The fact that these emitters can be operated at non-UHV pressures, do not require elevated temperatures or a high energy laser system, make them a very attractive alternative to conventional cathode technology.

The emission from a ferroelectric is believed to result from the expulsion of charge from the surface and sub-surface layers $[1,3]$. This effect occurs upon switching the internal polarization by a fast voltage pulse. Typical durations of the emitted beam, in a zirconium based material, can be of order 200 ns [4]. As the bound charge is quite high, $0.01-0.1 \mathrm{mc}-\mathrm{cm}^{-2}$, the resultant electric fields impart significant energy to the emitted electrons. This latter phenomena has been both verified by direct measurement [5] and explains measured current densities in excess of those predicted by the Child-Langmuir space charge limit for electrons with zero initial kinetic energy.

One of our motivations for pursuing ferroelectric emitter technology is upgrading the cathode brightness of the high power, pulsed accelerators at the, Lawrence Liver- 
more National Laboratory. The Advanced Test Accelerator or ATA (a $50 \mathrm{MeV}, 10 \mathrm{kA}$ electron accelerator) [6] and the Flash X-Ray Řadiography Accelerator or FXR (a $20 \mathrm{MeV}, 4$ kA electron accelerator) [7] utilize velvet cathodes for electron production. Although simple, brightness is typically an order of magnitude below that of a high brightness dispenser cathode used on the Experimental Test Accelerator II (a $7.5 \mathrm{MeV}, 2.5 \mathrm{kA}$ electron accelerator) [8]. To implement a dispenser cathode on either accelerator, however, would require major upgrades to the injector. In addition, there are applications where gating the electron beam is required. Again, significant modifications to the injector would be required in these applications.

Recent data taken at $4 \mathrm{~A}-\mathrm{cm}^{-2}, 15 \mathrm{~A}$ total, showed a

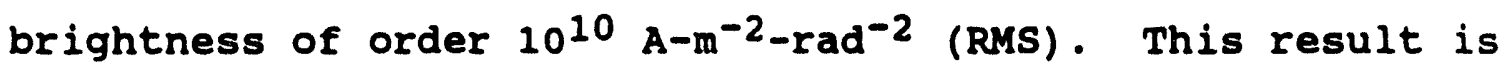
shown comparatively in Figure 1. The experiment used a 1-2 $\mathrm{kV}$ inversion pulse with a variable DC power supply across the anode-cathode (A-K) gap [2], i. e., emission was controlled by the inversion pulse. This data was taken at an A-K potential of $10 \mathrm{kV}$.

It is the eventual purpose of our effort to determine if a similar brightness is attainable for kiloampere electron beams. Further, as the emission appears to be dependent on the inversion pulse, we are also trying to determine to what extent the emission can be controlled by the inversion pulse. We report on our apparatus and preliminary measurements. 
2. Apparatus

The cathode test stand is shown schematically in Figure 2. This apparatus was previously used to measure brightness of osmium coated dispenser cathodes, but was modified to allow exploration of ferroelectric emitters [9].

A pre-poled, $1 \mathrm{~mm}$ thick $\times 5.1 \mathrm{~cm}$ diameter Lead Titanate-zirconate Piezo Ceramic (LTZ-2) [10] was placed behind a highly transparent grid. The emission side was optically polished; the grid was a square mesh composed of $0.025 \mathrm{~mm}$ diameter tungsten wires spaced approximately $0.75 \mathrm{~mm}$ on centers. Sample orientation was such that the bound positive charge (negative screening charge) was positioned toward the A-K gap. All but a $3 \mathrm{~cm}$ diameter central area of the sample was apertured. The grid-emitter assembly was recessed into the cathode shroud approximately $0.4 \mathrm{~cm}$; the distance from the emitter surface to the anode was approximately $1.8 \mathrm{~cm}$. A copper plate mask, $0.16 \mathrm{~cm}$ thick, served as the anode. The entire vacuum system and housing was fabricated from stainless steel; ceramics are used as insulators. Turbo-molecular pumps were used throughout. Base pressures in the $10^{-7} \mathrm{~T}$ range were easily achieved and maintained.

Main current was measured by resistive current monitors; A-K potential was measured by a capacitive probe calibrated by a standard resistive probe. Data was recorded with fast analog oscilloscopes.

Core brightness measurements were attempted with a 
single $100 \mu$ hole aperture and fast phosphor 2 no(Ga). A mask consisting of nine $360 \mu$ holes placed in an "X" pattern and a slow phosphor (P20) was later used. Charging was eliminated with a conductive film placed over the phosphor. Drift distance from the anode mask to the phosphor was $24.5 \mathrm{~cm}$. Microchannel plate intensified, CCD gated cameras, allowed observation of the phosphor image. Minimum gate width was 5 ns.

The polarization inversion pulse was coupled to the back plane of the ferroelectric emitter via a short length of $10 \mathrm{ohm}$, coaxial cable. The modulator system was at ground potential while the ferroelectric assembly and cathode stalk were elevated to the accelerating potential. The anode was maintained essentially at ground potential through the resistive current monitor. A stack of ferrite material placed along the 10 ohm coaxial cable provided the isolation impedance from the cathode stalk to ground. In these initial measurements, the system is mismatched so that ferrite reset was provided by the arrival of the first positive reflection; electron current was then initiated at the following reversed polarity pulse.

A polarization inversion pulse was supplied by a set of 32 planar triodes in parallel (Figure 3) [11]. A total current of approximately $0.5 \mathrm{kA}$ at a maximum voltage of 20 kV could be obtained by discharging a $0.05 \mu F$ capacitor connected to the ferroelectric backplane via the $10 \mathrm{ohm}$ coaxial cable. The bandwidth of the system was approximately $50 \mathrm{MHz}$. 
The high voltage pulsed power was supplied by a water filled blumlein. For double pulse capability, we used a magnetically delayed low pressure switch (MDLPS) [12]; double pulses as closely spaced as $50 \mu$ sere possible. The system was capable of $5 \mathrm{~Hz}$ continuous repetition rate. The blumlein and power supply system were capable of output pulses on the order of $250 \mathrm{kV}$ into $12 \mathrm{ohm}$.

3. Experimental Results

Emission from the ferroelectric emitter was achieved with a negative $2 \mathrm{kV}$ square pulse, $100 \mathrm{~ns}$ in length. Approximately 20,000 shots were placed on the ferroelectric emitter at 1 pps with no discernable degradation in the emission characteristics. A-K potential was varied from approximately 15 to $60 \mathrm{kV}$. Peak currents of approximately 150 A were achieved during these initial measurements. As was generally observed, the measured currents were unipolar, consistent with electron flow, and above the childLangmuir limit, $J_{C L}$, for electrons with zero initial kinetic energy.

During the inversion processes, we sometimes observed multiple discharges between the wire mesh and the ferroelectric emitter. In addition, upon application of elevated A-K potentials, a time integrated photograph showed a brilliant discharge filling the $A-K$ volume (Figure 4 ). Never-the-less, unipolar current flow is generally observed.

To optimize the emission, timing between the inversion 
pulse and the main $A-K$ pulse was varied from approximately 580 to 320 ns prior to arrival of the main voltage pulse (Figure 5). For a fixed $A-K$ potential of $25 \mathrm{kV}$, the emitted current varied from approximately $0.5 \mathrm{~J}_{\mathrm{CL}}$ to $2.8 \mathrm{~J}_{\mathrm{CL}}$ over this timing variation. The optimum timing varied sharply about the peak showing a 258 decrease in the emission current for a timing variation of $+/-20$ ns from the optimum.

The emitted current from the ferroelectric was measured as a function of the applied A-K potential (Figure 6). In this data, the A-K potential was varied from $16 \mathrm{kV}$ to 41 $\mathrm{kV}$; the emitted current varied from $32 \mathrm{~A}$ to $85 \mathrm{~A}$. A significant amount of scatter was present in the data and consistent with those previously measured by others [4]. The data indicated that the emitted current exceeded $J_{C L}$, on average, by a factor of approximately two.

Initial brightness measurements were attempted with both the single aperture mask and fast phosphor and the multi-aperture mask and slow phosphor. A-K potential and polarization inversion pulse to the applied $A-K$ potential timing were varied. The inversion pulse potential for this data was $2.4 \mathrm{kV}$. Data was taken at A-K potentials of $11 \mathrm{kV}$ and $21 \mathrm{kV}$. Peak gap current varied from $6 \mathrm{~A}\left(0.9 J_{C L}\right)$ at $11 \mathrm{kV}$ to $42 \mathrm{~A}(4.7 \mathrm{~J} C L)$ at $21 \mathrm{kV}$.

Brightness measurements with the single aperture mask and fast phosphor were unsuccessful. Upon installing the multi-aperture mask and slow phosphor, we were able to observe severe distortion of the mask pattern on the phos- 
phor. Further, the mask image and the intensity of the image of the beamlets at the phosphor was inconsistent from shot-to-shotrat the lower $A-K$ potential.

From the expansion of the beamlets, and inferring the space-charge expansion by aperture hole size and current density at the cathode surface, we estimated the lower bound of the beam brightness. As in similiar measurements [9], we estimated this lower bound at $10^{9} \mathrm{~A} / \mathrm{m}^{2}-\mathrm{rad}^{2}$ at current densities below $1.7 \mathrm{~J}_{\mathrm{CL}} ;$ at a current density of $4.7 \mathrm{~J}_{\mathrm{CL}}$ we estimated the lower bound to be of order $5 \times 10^{8}$ $A / m^{2}-\operatorname{rad}^{2}$.

4. Discussion

A Child-Langmuir solution for charged particles with non-zero initial kinetic energy is presented in the Appendix. It is shown that the increased current results from two effects. The first is a contraction of the effective A-K gap to the distance between the virtual cathode formed beyond the ferroelectric surface and the anode. The second arises from an effective increase in the $A-K$ potential due to the initial electron energy. From Figure 6 and Equation A-13, we infer the initial electron energy to be approximately $5 \mathrm{keV}$.

This initial energy is 2.5 times the energy that can be imparted by the polarization inversion pulse of $2 \mathrm{kV}$. We presume that the increased energy results from the exposed bound charge after the polarization inversion [1].

The observed luminescence from the cathode surface 
would indicate plasma formation on the ferroelectric surface. The increased emitted current density, however, indicated a high initial electron energy. This increased electron energy is generally inconsistent with emission from a plasma cathode. Further, late time gap closure is generally observed with a plasma cathode. Late time closure was not observed here or reported in other ferroelectric emitter experiments with a DC A-K potential [2]. These preliminary facts led us to believe that the main emission process was different than that of a simple plasma cathode.

A strong dependence of the emitted current on the relative timing of the polarization inversion pulse to the applied A-K potential existed. Optimized electron emission occurred within a relatively narrow timing window.

Application of the $A-K$ potential early would result in decreased electron current from the ferroelectric surface if a non-zero time was required for charge expulsion. Others presented data on the same ferroelectric material which indicated of order 50 ns rise-time to peak emission current [4].

Decreased electron currents from late $A-K$ potential application could be explained by electron diffusion from between the A-K region. Qualitatively, the ejected screening charge would produce a radial electric field component which would impart transverse energy to the emitted electrons. With no acceleration potential, diffusion of the electron cloud and decreased electron densify would result. 
Application of the A-K potential late would also result in decreased currents.

The brightness measurement attempted using the single aperture in the anode copper plate mask was unsuccessful. The reason was evident from the second measurement in that the emission we observed showed that the trajectories at the anode mask varied significantly from shot-to-shot. Beam uniformity also varied. It is not clear at this point what effect the discharge on the cathode surface had on our overall result. In our upcoming experiments, we will attempt to modify the grid structure to minimize discharges on the cathode surface.

5. Summary

We have begun initial experiments on ferroelectric emitters. As with previous researchers, we observed emitted currents greater than the Child-Langmuir space charge currents for electrons emitted with zero initial energy. To explain this effect, we qualitatively concluded that the emitted energy was non-zero. Further, we deduced that the emitted energy was significantly above that which the polarization pulse could impart to the emitted beam. A plasma discharge was observed on the ferroelectric surface. Based on our observations, however, we believe that the emission process was not dominated by this plasma. Optimization of the polarization inversion pulse timing qualitatively indicated that the electron cloud formed on the surface of the ferroelectric surface did nat occur instan- 
taneously and further, decayed on approximately the same time scales. Our preliminary brightness measurement was of order $10^{9} \dot{A} / \mathrm{m}^{2}-\mathrm{rad}^{2}$. We will be modifying the grid structure on the ferroelectric surface and will make additional measurements.

6. References

[1] H. Gundel, H. Riege, J. Handerek, and K. Zioutas, CERN Report NO. CERN/PS/88-66 (AR), 1988 .

[2] G. Kirkman, B. Jiang, and N. Reinhardt, presented at the International Electron Devices Meeting (San Francisco, California, 1992).

[3] L. Schachter, J. D. Ivers, J. A. Nation, and G. S. Kerslick (to be published in the J. Appl. Phys.)

[4] J. D. Ivers, R. Advani, J. A. Nation, and I. Schachter, in Conference Record of the 1991 IEEE Particle Accelerator Conference, (San Francisco, California, USA, 1991), pp. 2104-2106.

[5] H. Gundel, H. Riege, E. J. N. Wilson, J. Handerek, and K. Zioutas, Nucl. Instrum. Methods A280, 1-6 (1989).

[6] L. L. Reginato, presented at the 1983 Particle Accelerator Conference (Santa Fe, New Mexico, USA, 1983).

[7] B. Kulke, D. S. Ravenscroft, and G. E. Vogtlin, presented at the 1981 Particle Accelerator Conference (Washington, DC, USA, 1981).

[8] J. C. Clark, et. al., presented at the Linear Accelerator Conference (Williamsburg, Virginia, 1988).

[9] W. C. Turner, Y.-J. Chen, W. E. Nexsẹn, M. C. Green, 
G. Miran, and A. V. Nordquist, presented at the 1988 Linear Accelerator Conference (williamsberg, Virginia, USA, 1988).

[10] Transducer Products, Route 63 North, Goshen, Connecticut, USA.

[11] E. E. Bowles and W. C. Turner, in the Digest of Technical Papers, 7 th IEEE Pulsed Power Conference, (Monteray, California, 1989), pp. 43-46.

[12] S. E. Sçpayan, H. C. Kirbie, E. Lauer, A. N. Payne, and D. Prosnitz, to be published in the pigest of Technical Papers, 9th IEEE Pulsed Power Conference, (Albuquerque, New Mexico, USA, 1993). 


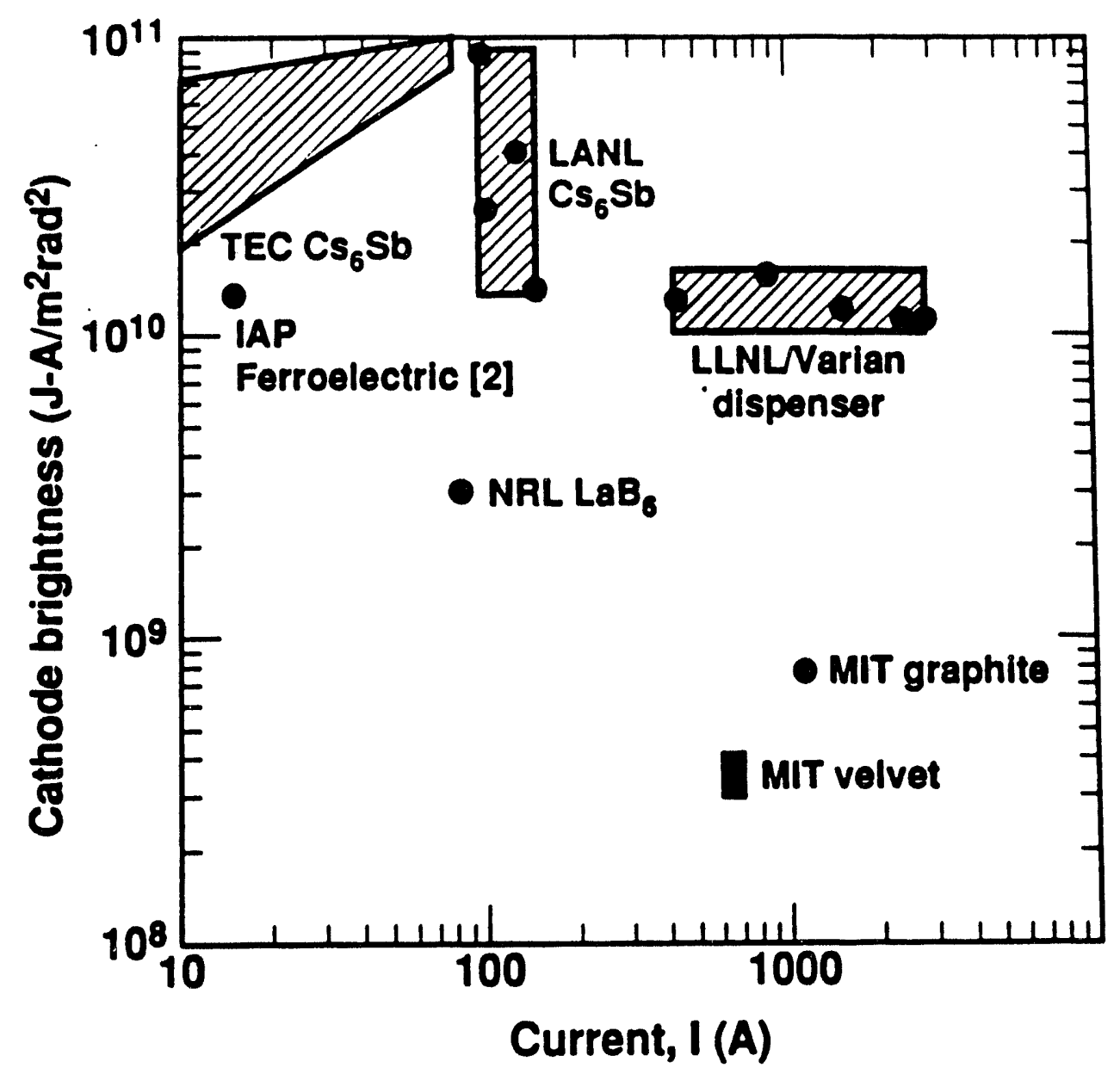

Fig. 1 


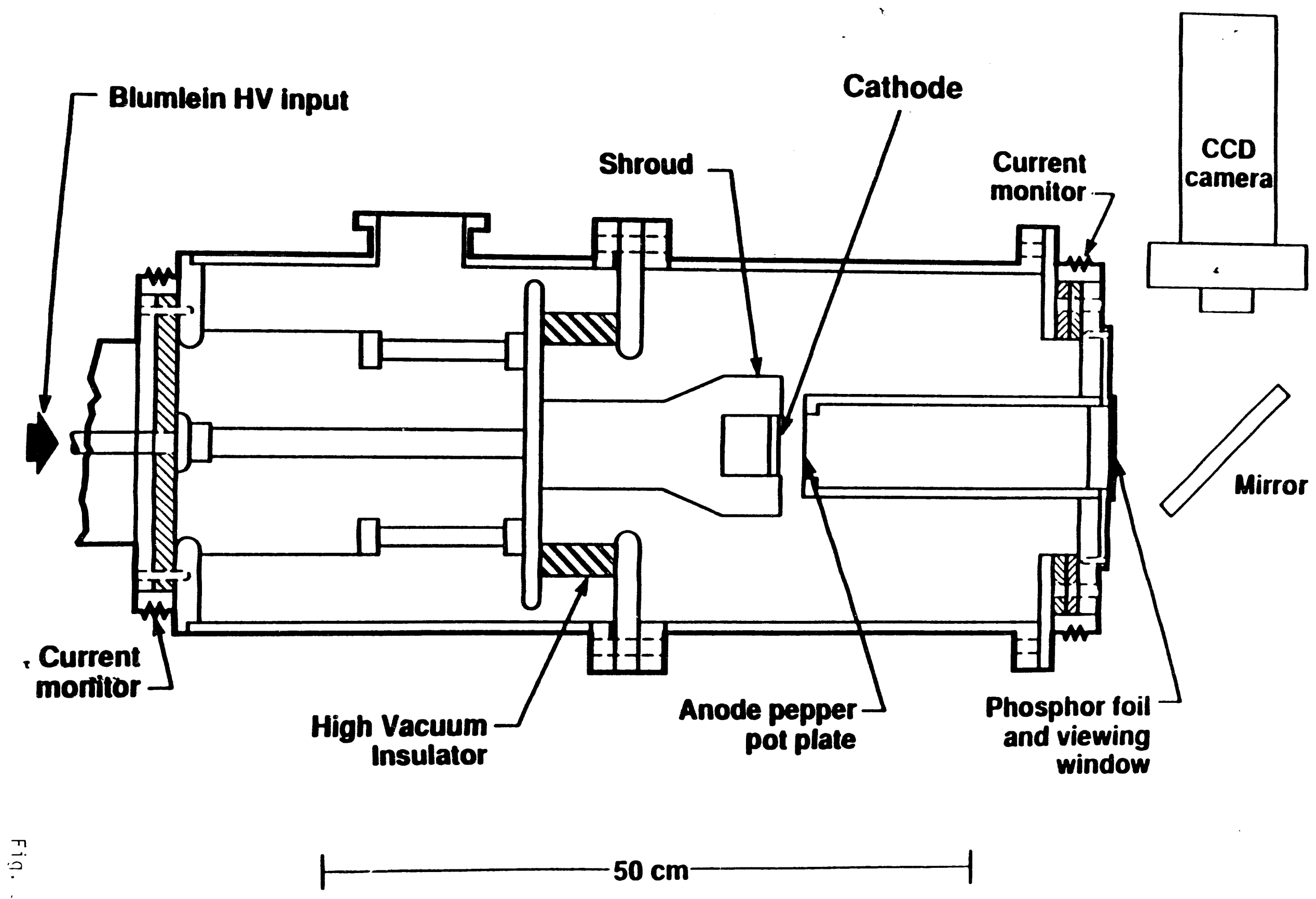




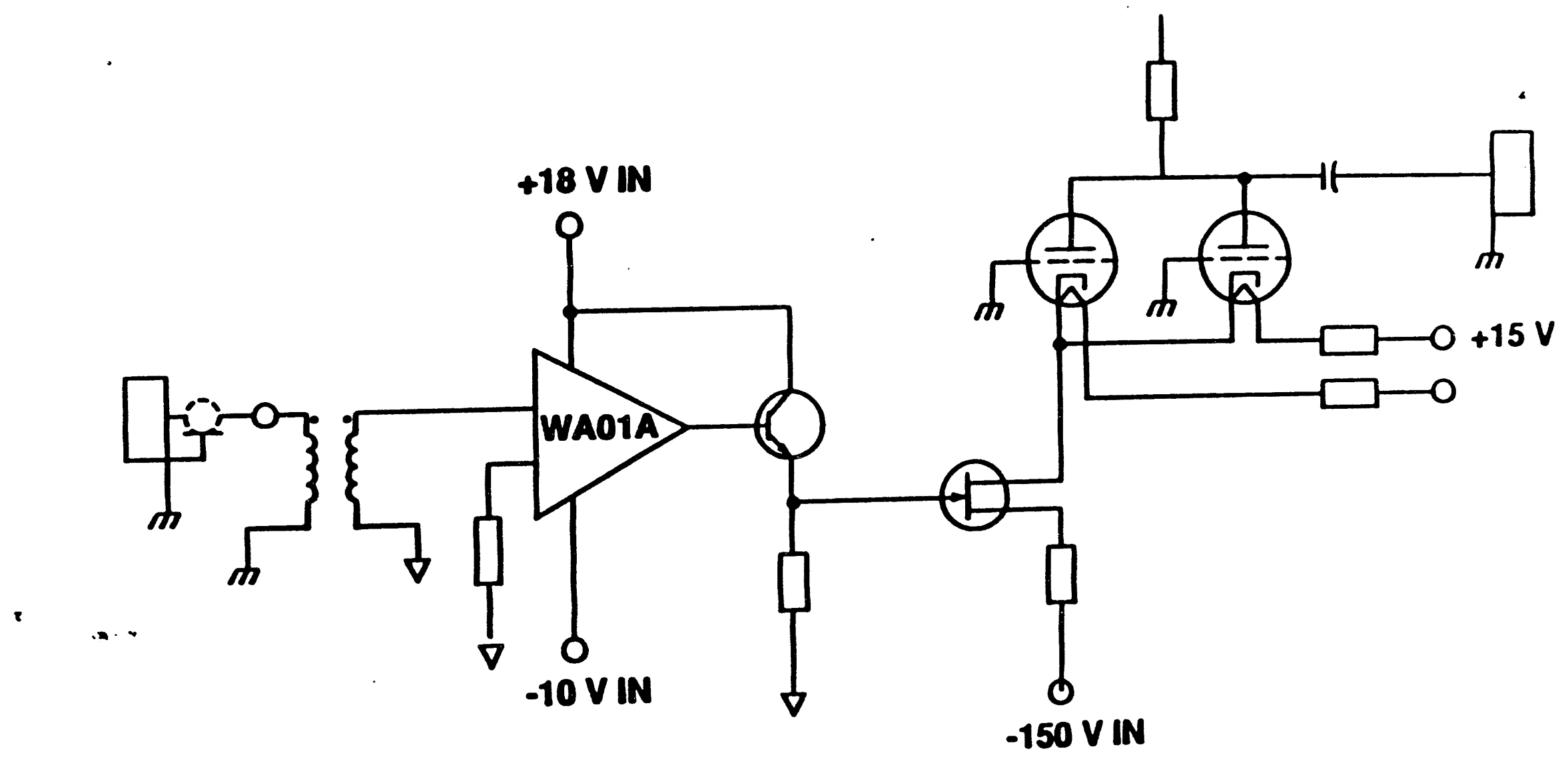

ก. 


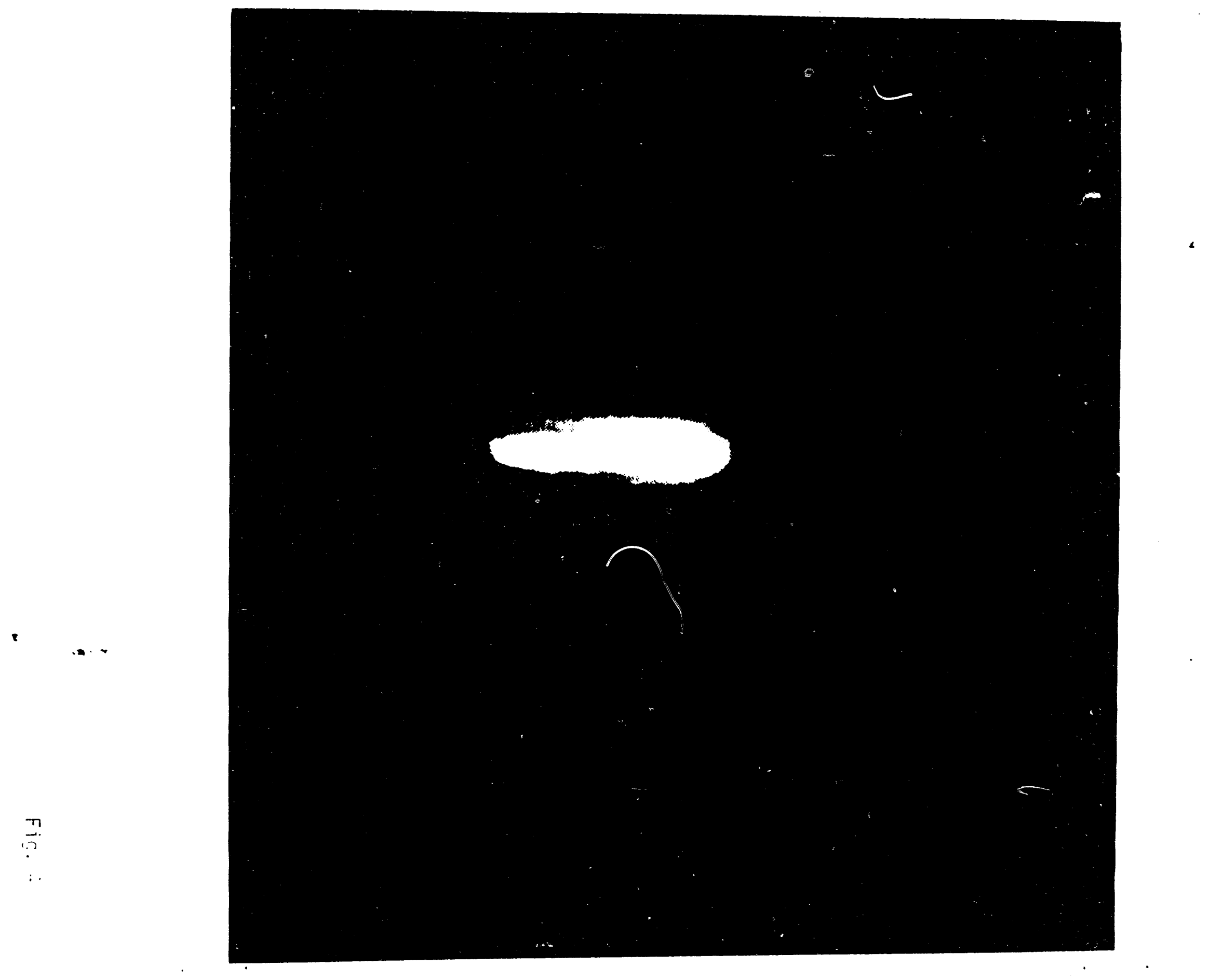




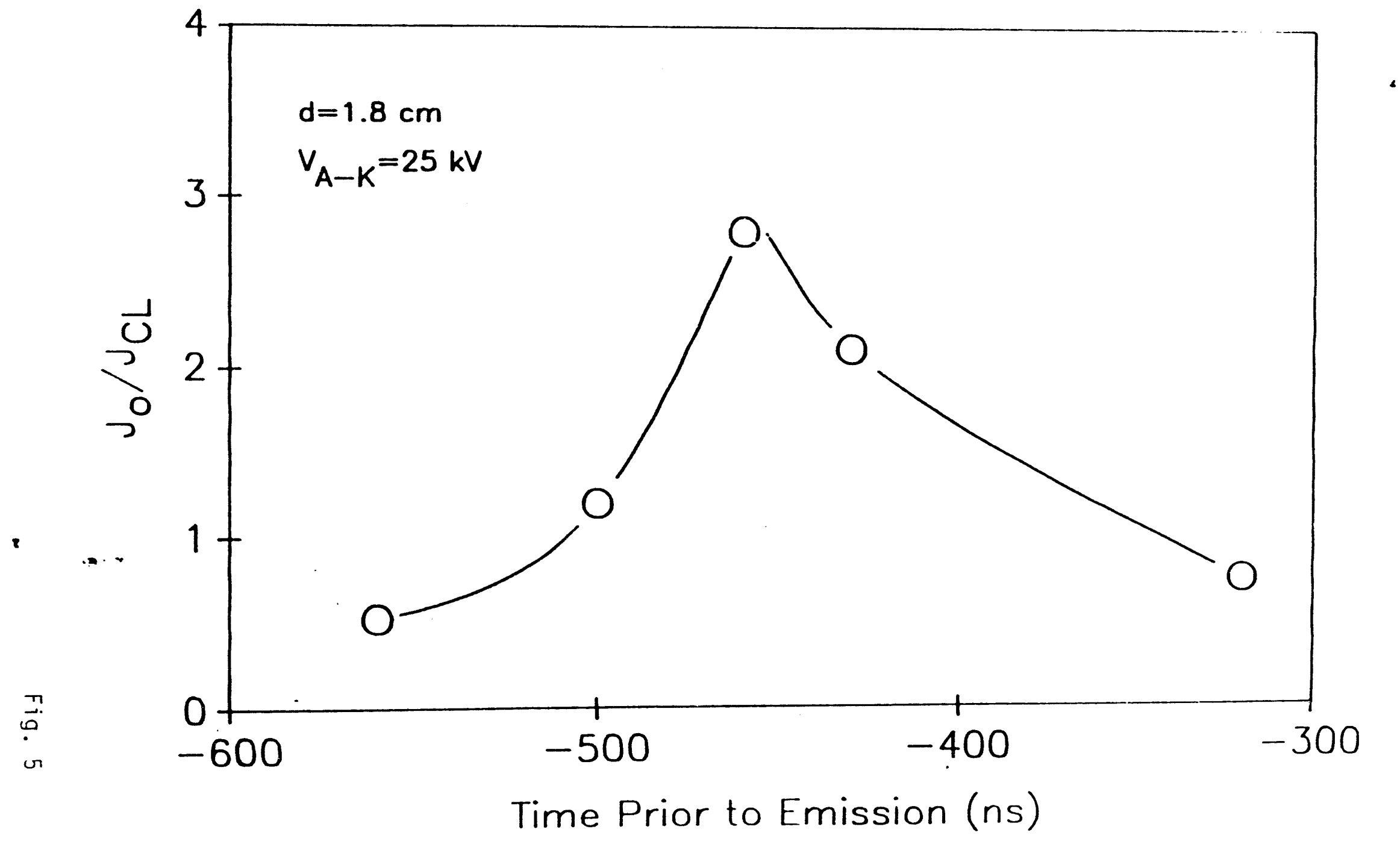

OSI JFPI GRA 


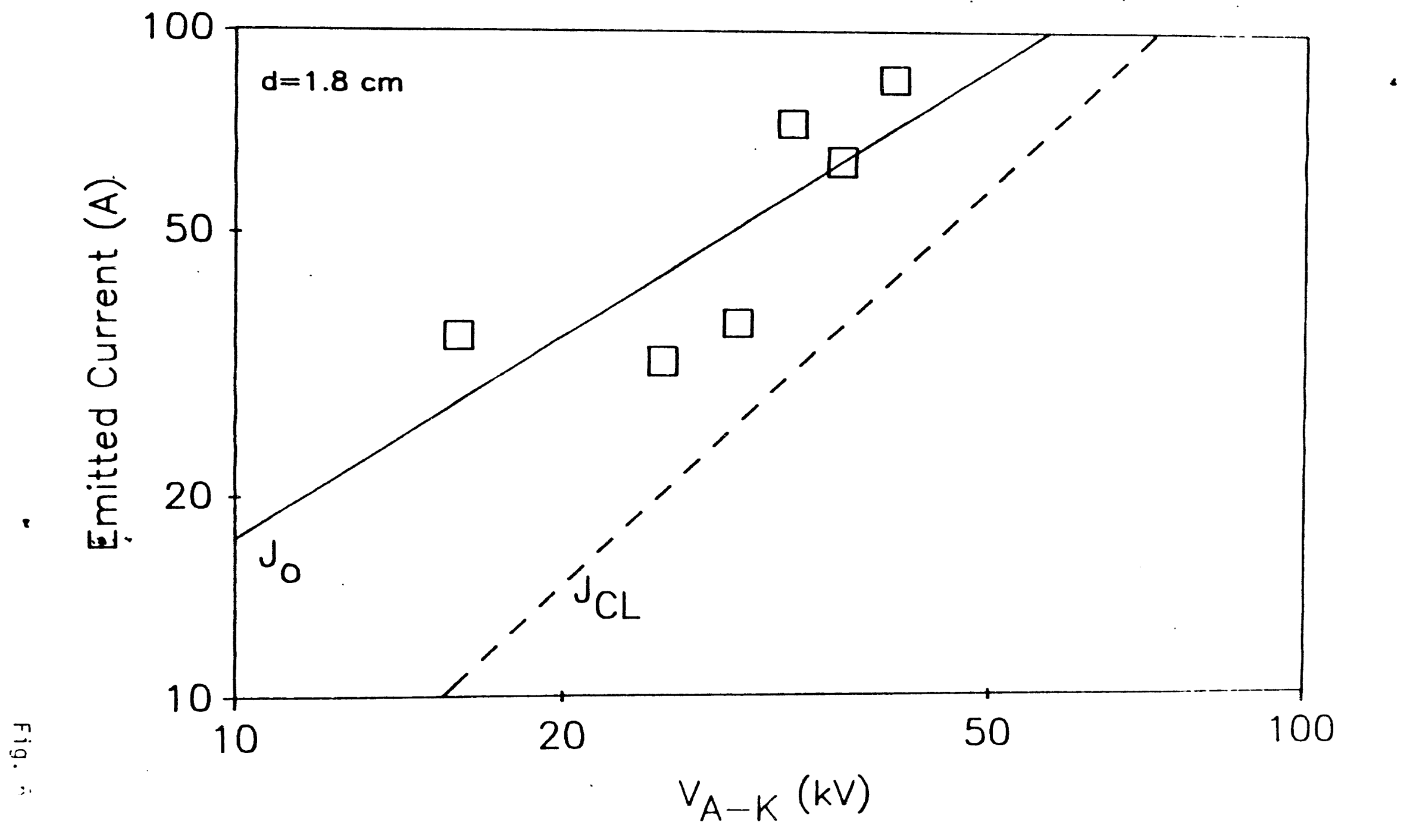

OSI 7FP2.CRA 


\section{APPENDIX}

\section{Child-Langmuir Solution With Non-zero Initial Electron Velocities}

We consider the p-oblem of a one dimensional, non-relativistic electron diode where the electrons are assumed to be launched with some initial, non-zero velocity. We assume for simplicity that the distribution of initial elpctron velocities is a delta-function. We will also assume that the pulse length is much longer than the time it takes an electron to cross the A-k gap so that the electron flow is in steady state.

Without loss of generality we take the potential $\phi$ to be zero at the cathode. If $x$ represents the distance along the axis of the diode then the equation of motion of an electron is given by

$$
\nu \frac{\partial v}{\partial x}=\frac{e}{m} \frac{\partial \phi}{\partial x}
$$

which may be immediately integrated to give

$$
v^{2}=v_{0}^{2}+\frac{2 e \phi}{m}
$$

where $v_{0}$ is the initial velocity of the electron at the cathode. Sirice the initial electron velocity is non-zero an electron can more easily overcome the space charge potential barrier in the A-k gap. Thus, the current that must be emitted in order to satisfy the condition for space charge limited flow will be larger than in the case of zero initial velocity. As a result, the increased space charge (due to the increased current) will cause the electrons to decelerate until a virtual cathode is formed where $v=0$ (see figure $A-1$ ) at $x=x_{v}$. This will occur when the potential reaches its minimum value

$$
\phi_{\min }=-\frac{m v_{0}^{2}}{2 e} .
$$

Beyond the virtual cathode, the electrons will accelerate again until they reach the anode.

To proceed further with the development we must use Poisson's equation

$$
\frac{d^{2} \phi}{d x^{2}}=-4 \pi \rho
$$

First we note that in the steady state, current is conserved so that we may write the charge density $\rho$ as

$$
\rho=-\frac{J_{0}}{v}=-\frac{J_{0}}{\sqrt{v_{0}^{2}+\frac{2 e \phi}{m}}}
$$

where $J_{0}$ is the magnitude of the (constant) diode current density. 
It will prove convenient to define a dimensionless potential $\psi \equiv 2 \mathrm{eO} / \mathrm{m} \%$. Then equations $A-4$ and $A-5$ can be cominined to yield

$$
\frac{d^{2} \psi}{d x^{2}}=\frac{\alpha}{\sqrt{1+\psi}}
$$

where the quantity $\alpha$ is defined as

$$
\alpha \equiv \frac{8 \pi e J_{0}}{m v_{0}^{3}} .
$$

We may integrate equation A-6 immediately to obtain

$$
\frac{\psi^{\prime 2}}{2}=B+2 \alpha \sqrt{1+\psi}
$$

where $B$ is a constant of integration and where a prime denotes differentiation with respect to $x$. We note that at the virtual cathode $\left(x=x_{v}\right)$ we have $\psi=-1$ and $\psi^{\prime}=0$. Thus we have that

$$
\psi^{\prime}= \pm \sqrt{4 \alpha}(1+\psi)^{1 / 4}
$$

From figure A-1 we see that $\psi$ has the value zero at the cathode and decreases towards the virtual catinode. Thus in this region we choose the negative sign in equation A-9 which may then be integrated to give $x_{v}$, the position of the virtual cathode

$$
x_{v}=-\frac{1}{\sqrt{4 \alpha}} \int_{0}^{-1} \frac{d \psi}{(1+\psi)^{1 / 4}}=\frac{2}{3 \sqrt{\alpha}} .
$$

We can now integrate equatic A-9 (choosing the plus sign) from the virtual cathode to the anode which we take to be at $x=d$ to yield

$$
d-x_{v}=\frac{2\left(1+\psi_{0}\right)^{3 / 4}}{3 \sqrt{\alpha}}
$$

The quantity $\psi_{0}$ is the value of $\psi$ at the anode.

Adding equations $A-10$ and $A-11$ permits us to find the value of $\alpha$ as

$$
\alpha=\frac{4}{9} \frac{\left[1+\left(1+\psi_{0}\right)^{3 / 4}\right]^{2}}{d^{2}} .
$$

Using equation A-7 and the definition of $\psi_{0}$ we can write the current density $J_{0}$ as 


$$
\frac{J_{0}}{J_{C L}}=\frac{\left[1+\left(1+\psi_{0}\right)^{3 / 4}\right]^{2}}{\psi_{0}^{3 / 2}}
$$

where $\mathrm{JCL}_{\mathrm{C}}$ is the Child-Langmuir current density

$$
J_{C L}=\frac{1}{9 \pi} \sqrt{\frac{2 e}{m}} \frac{\phi_{0}^{3 / 2}}{d^{2}} .
$$

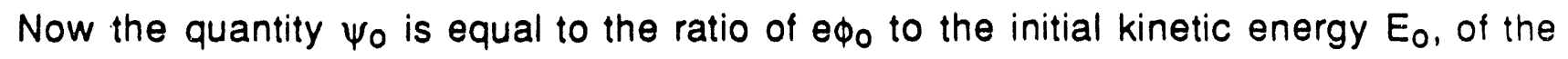
electrons. Equation $A-13$ is plotted against the ratio $E_{0} / e \phi_{0}\left(\right.$ or $\left.1 / \psi_{0}\right)$ in figure A-2. As this ratio becomes large we see that $J_{0}$ can become much larger than the Child-Langmuir current. An examination of figure A-1 shows how this can occur. The increase in current density arises from two effects. The first effect is a contraction of the effective A-k gap to the distance between the virtual cathode and the anode. The second effect arises from the increase in the effective djode voltage from $\phi_{0}$ to $\phi_{0}+E_{0} / e$. When the ratio of $E_{0} / e \phi_{o}$ becomes very large we see that the effective diode voltage becomes many times the applied voltage thus leading to very high current densities as compared to the Child-Langmuir current density. 


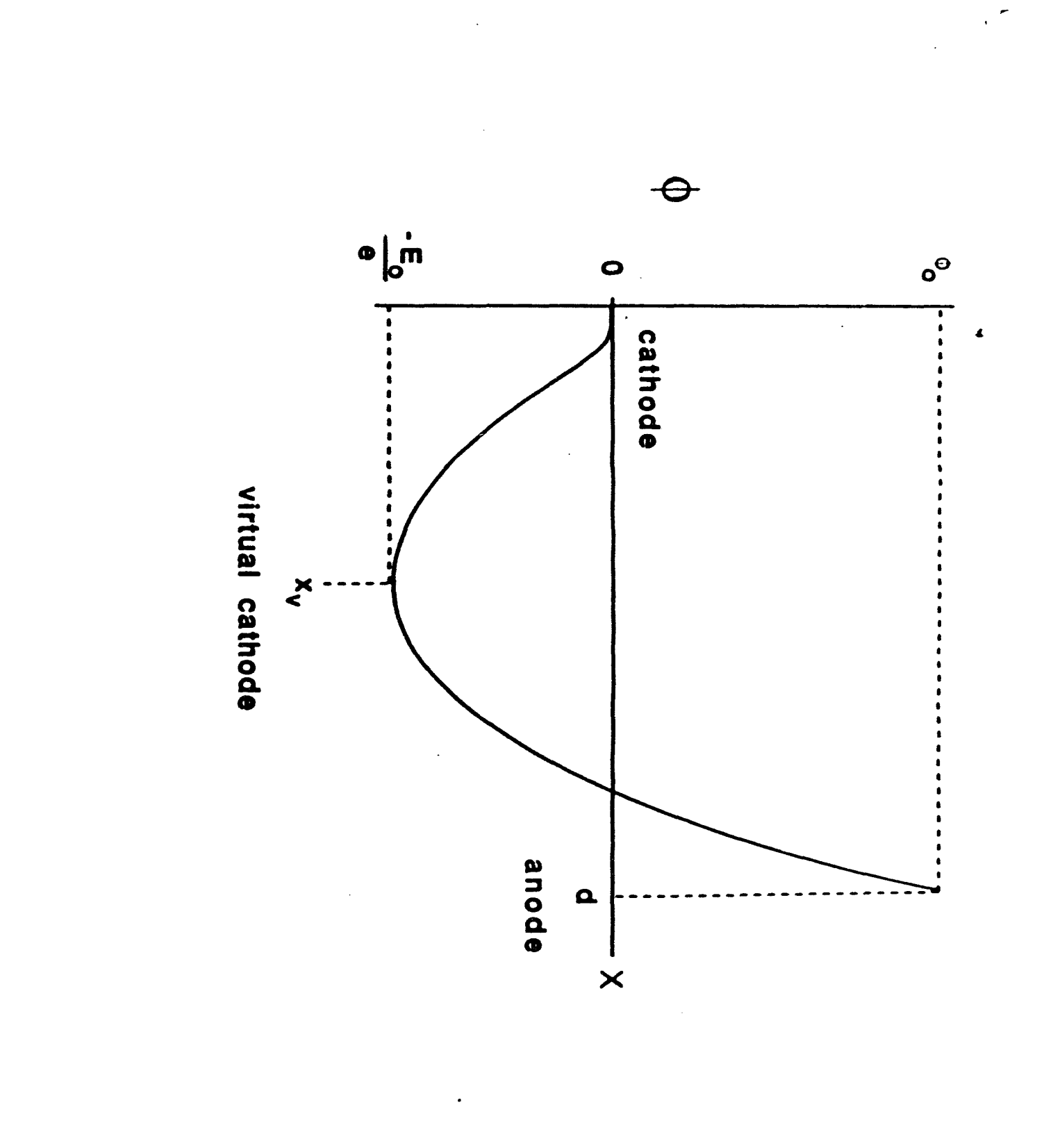




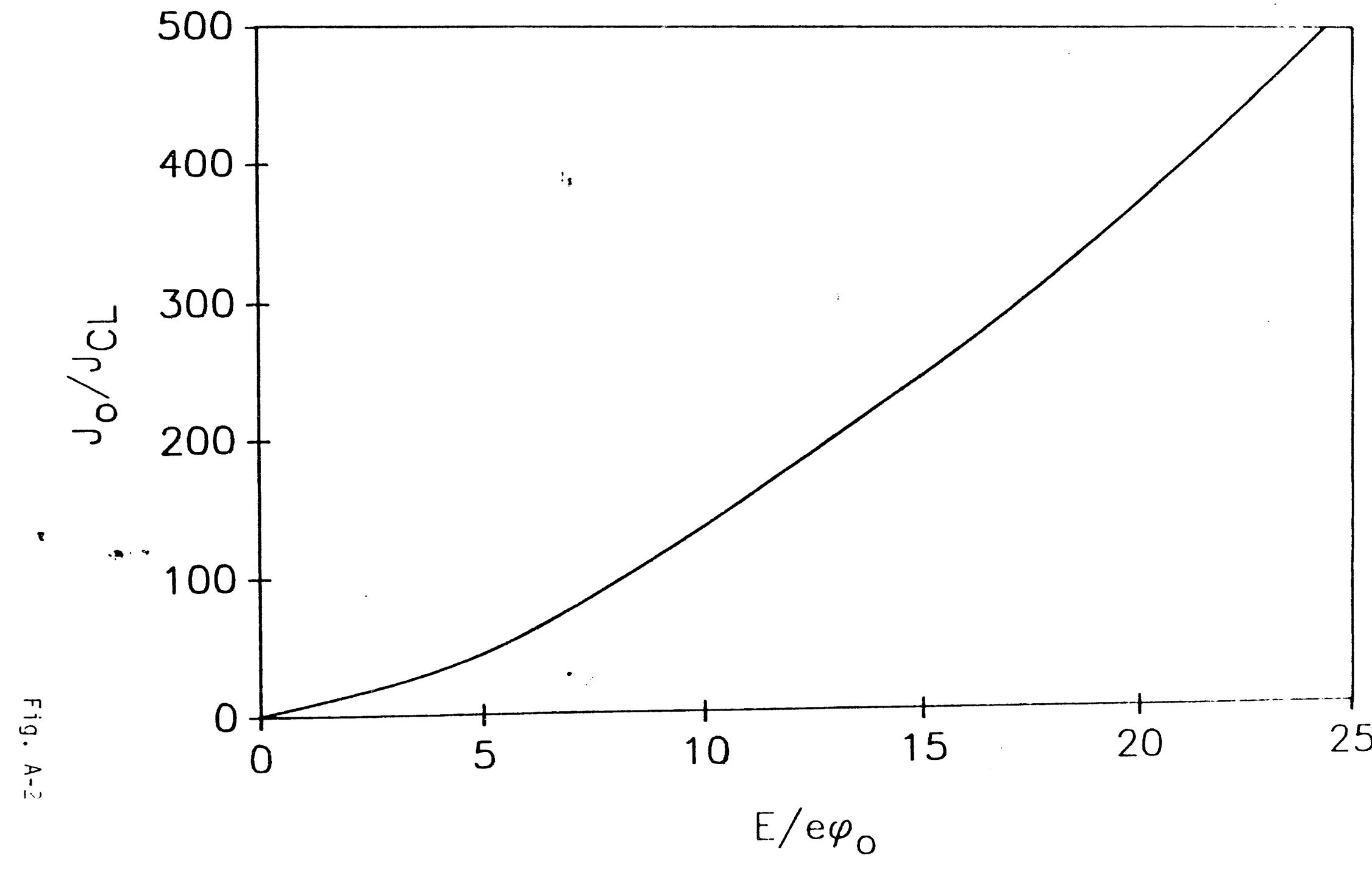

OSI IT S.CRA 


\section{Ferroelectric emitters appear promising as velvet}

cathode replacements for our induction linacs

- Motivated by results from CERN \& Cornell

$-\mathrm{j}>100 \mathrm{~A} / \mathrm{cm}^{2}$

- appears to have long life

- does not require UHV pressures

- Recent results by IAP show that ferroelectric emitters produce high brightness beams

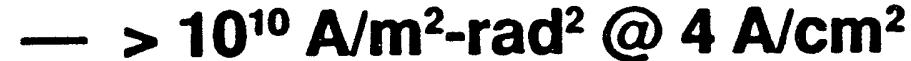

- material was Lead Titanate Zirconate

- 10kV A-K voltage 


\section{Other high brightness emitters exist but generally require operational pressures below $10^{-7} \mathrm{~T}$}

Induction accelerators can be easily upgraded with proven and reliable ferroelectric emitter technology

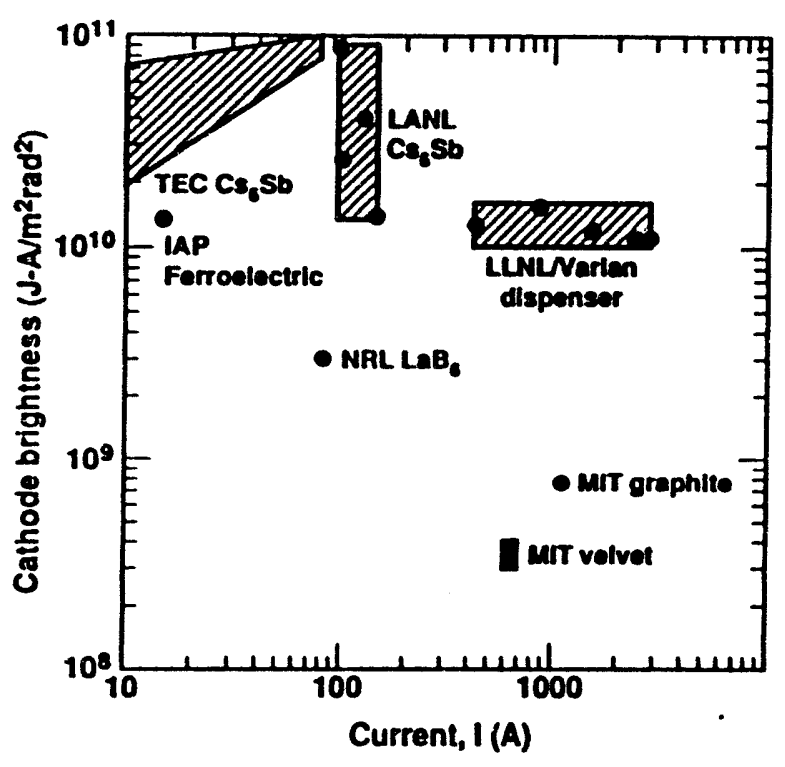

High brightness, high current emitters were demonstrated on ETA-II

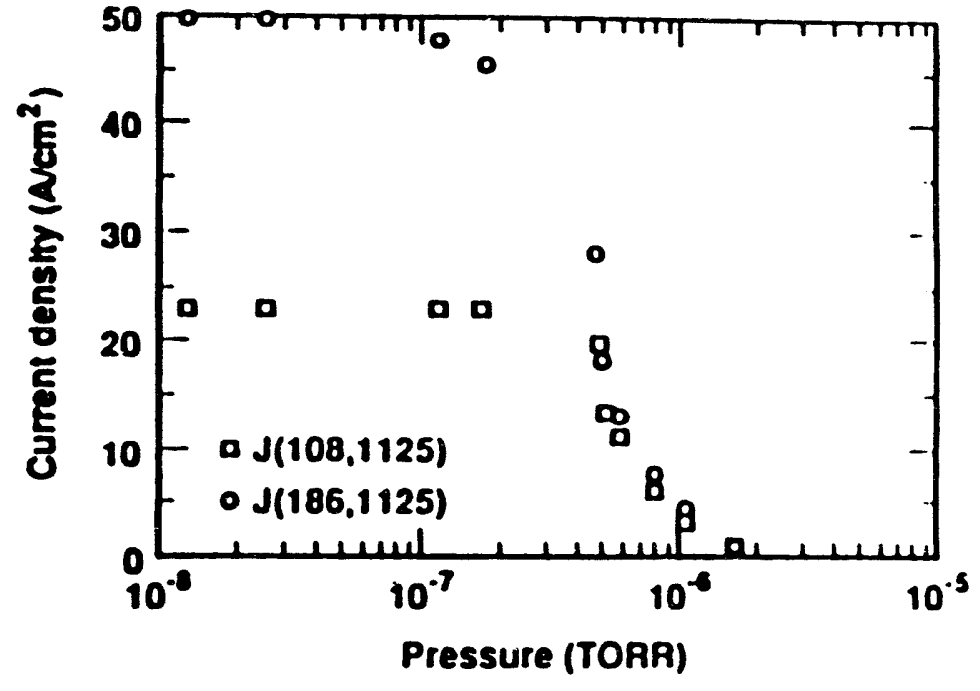

ETA-II type emitter technology is not usable above ${ }^{10^{-6}} \mathrm{~T}$ 


\section{High brightness cathodes are key development areas}

for high power induction accelerator technology

- FXR-DARHT-flash X-ray source

- high brightness cathode at minimum upgrade expense

- energy sweep correction by injector modulation

- Microwave source facility-relativistic klystron development

- $250 \mathrm{kV}, 100 \mathrm{~ns}$ pulse requirement at $<200 \mathrm{~Hz}$

- high brightness cathodes

- easily modulated injector 


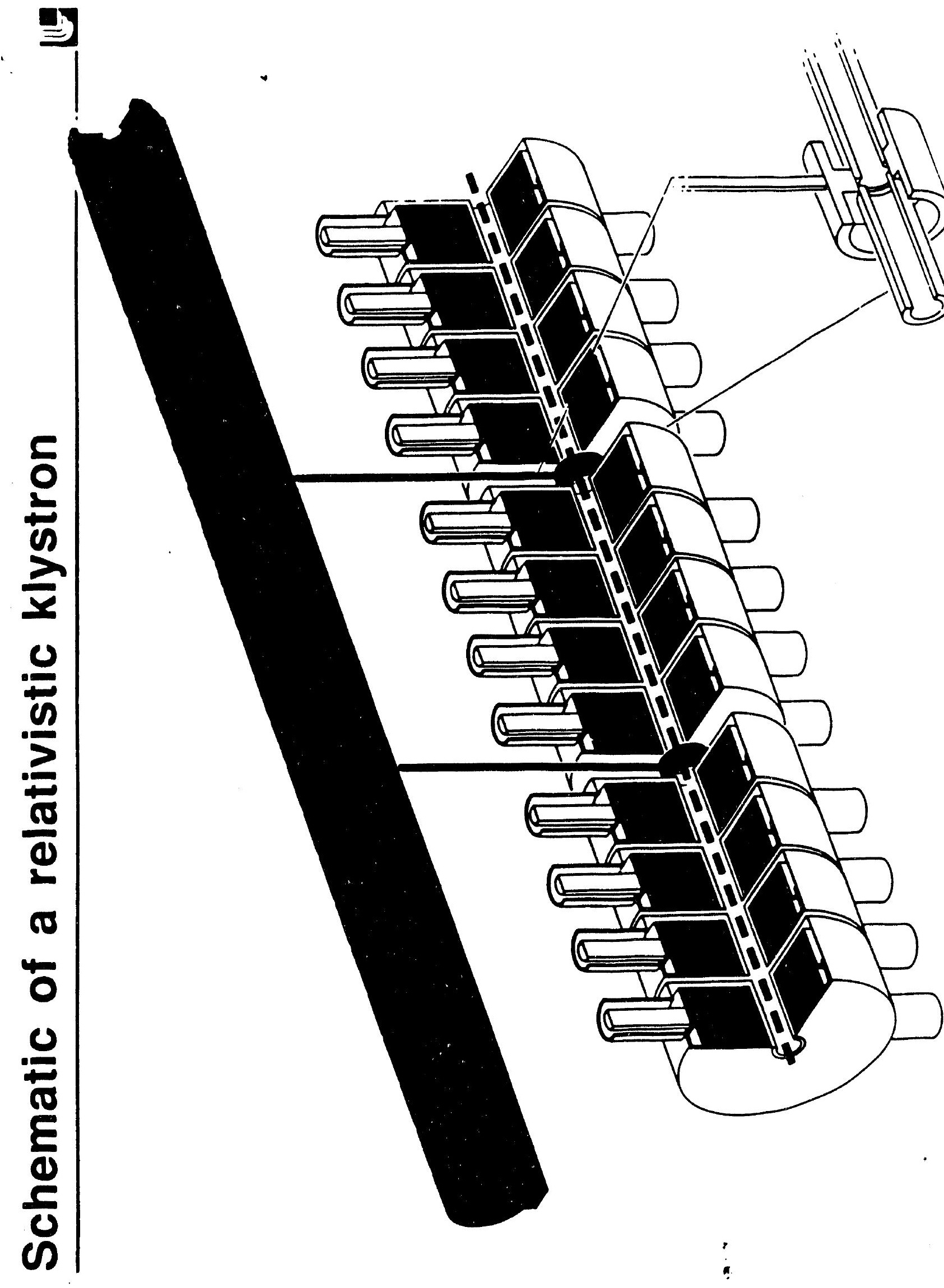




\section{Our ferroelectric emitter experiment has three components}

- Low pressure switch test stand (MDLPS)

- has provided $\approx 100 \mathrm{kV}$ into a matched load; system is capable of $250 \mathrm{kV}$

- rep-rate capability $>\mathbf{1 0} \mathbf{~ k H z}$ two pulse burst at $>5 \mathrm{~Hz}$ rep-rate

- Pulsed modulators

- utilizes planar triode amplifiers BW $70 \mathrm{MHz}$

- capable of $0.5 \mathrm{kA},>10 \mathrm{kV}$ output

- Cathode test stand

- capable of 250-350 kV A-K voltages

- existing hardware will allow studying $20 \mathrm{~cm}^{2}$ ferroelectric cathodes

- presently exploring lead titanate zirconate (LTZ-2, Transducer Products) 


\section{Operating sequence for the magnetically delayed switch}

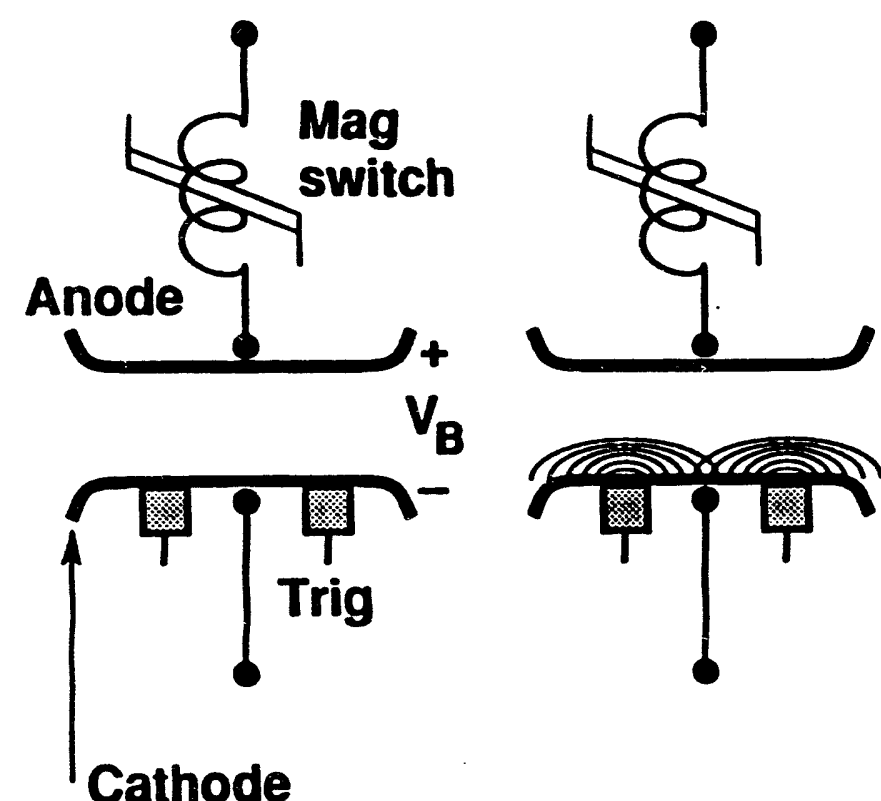

Switch is triggered from the cathode
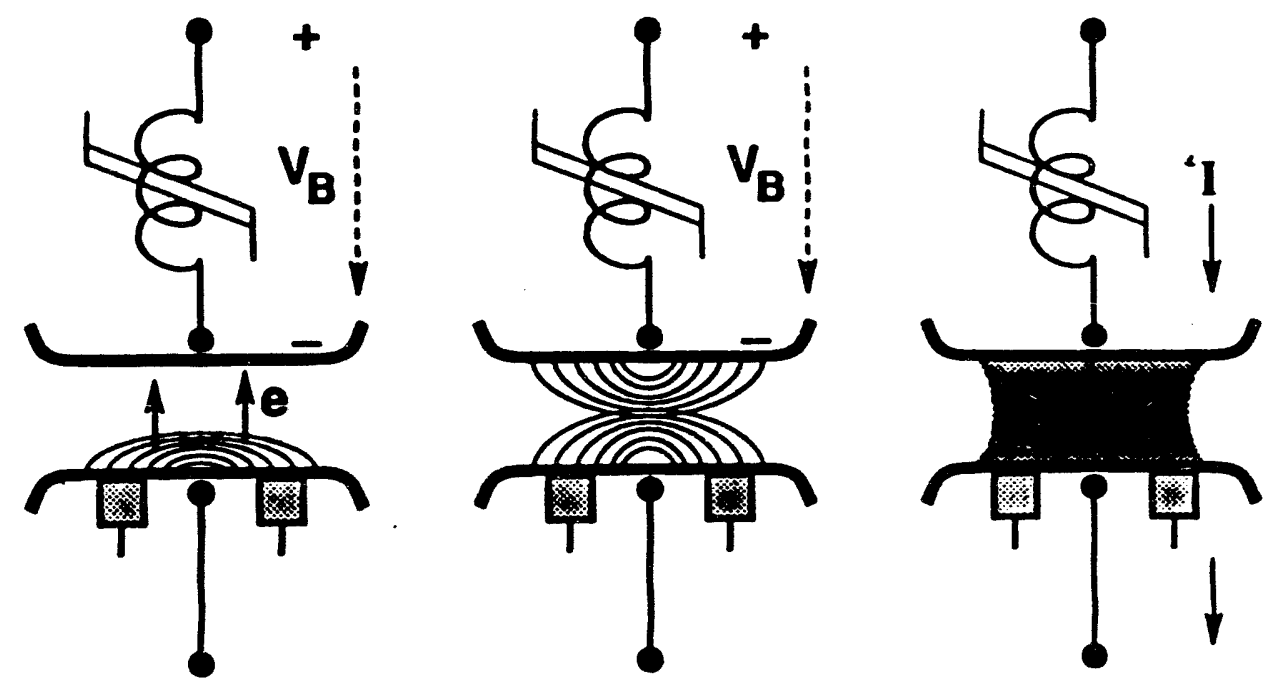
Electrons bombard anode
Leakage current flows

Anodecathode plasmas merge
Mag switch saturates to allow current to flow 


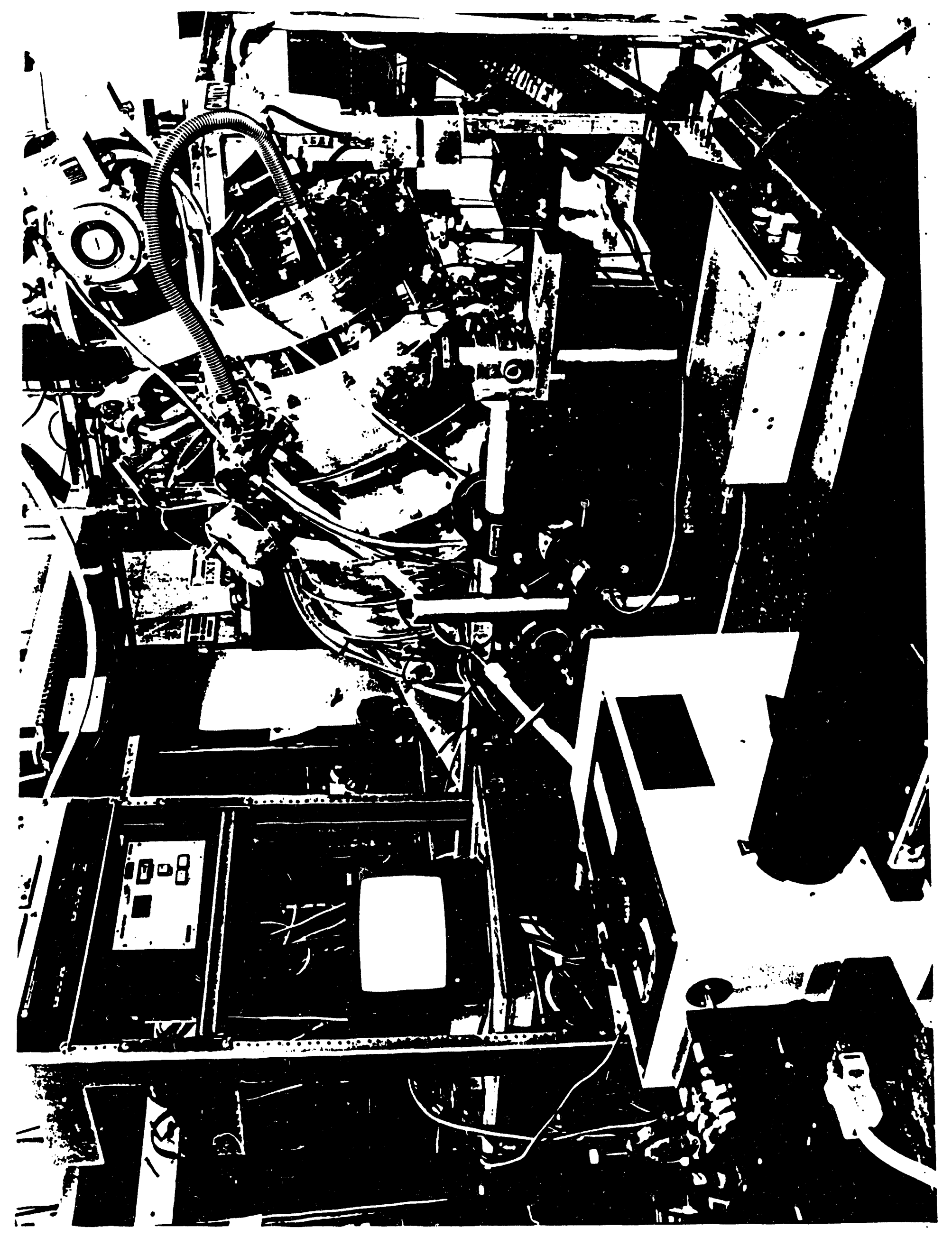




\section{Pulsed Modulator Schematic}
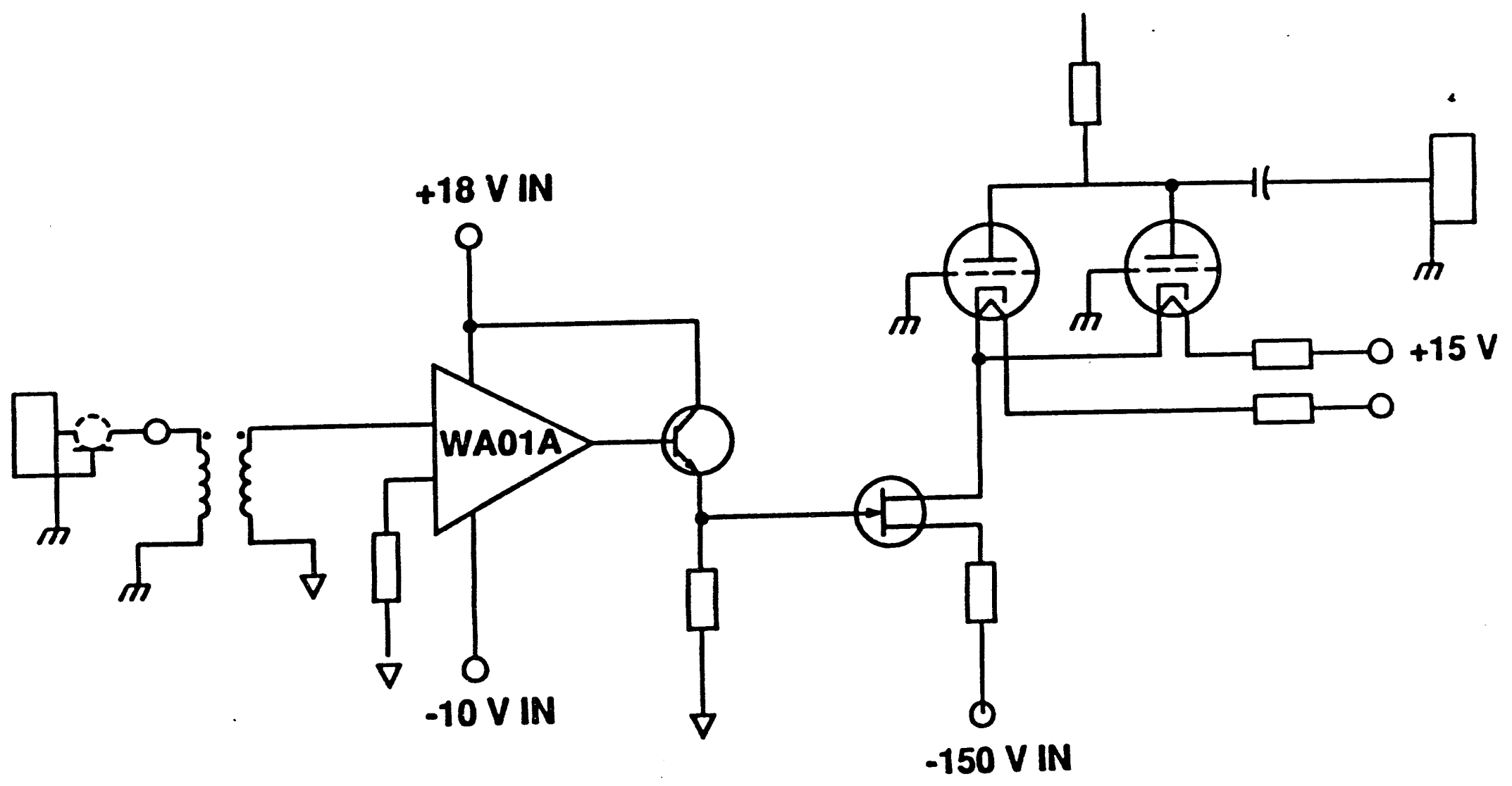


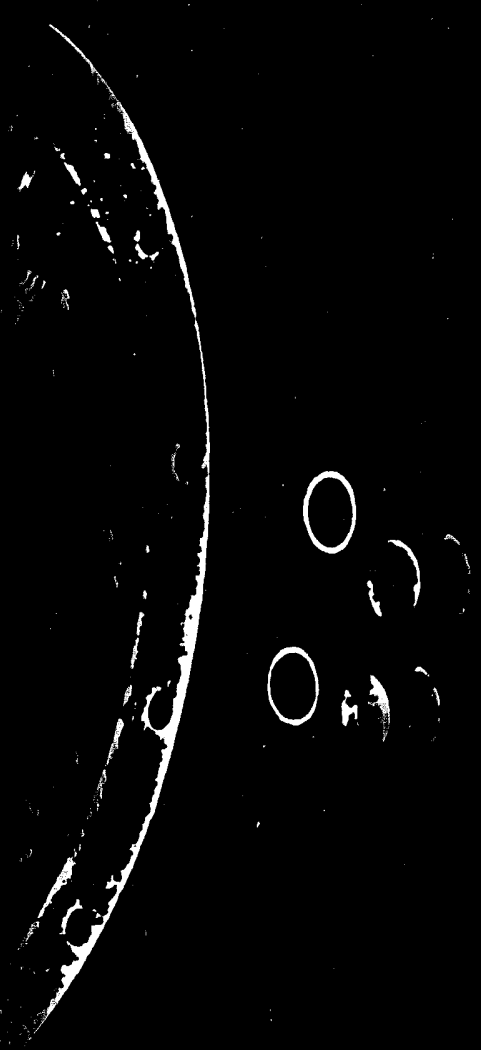

$\theta$ 


\section{Schematic of experimental apparatus}

to measure cathode brightness

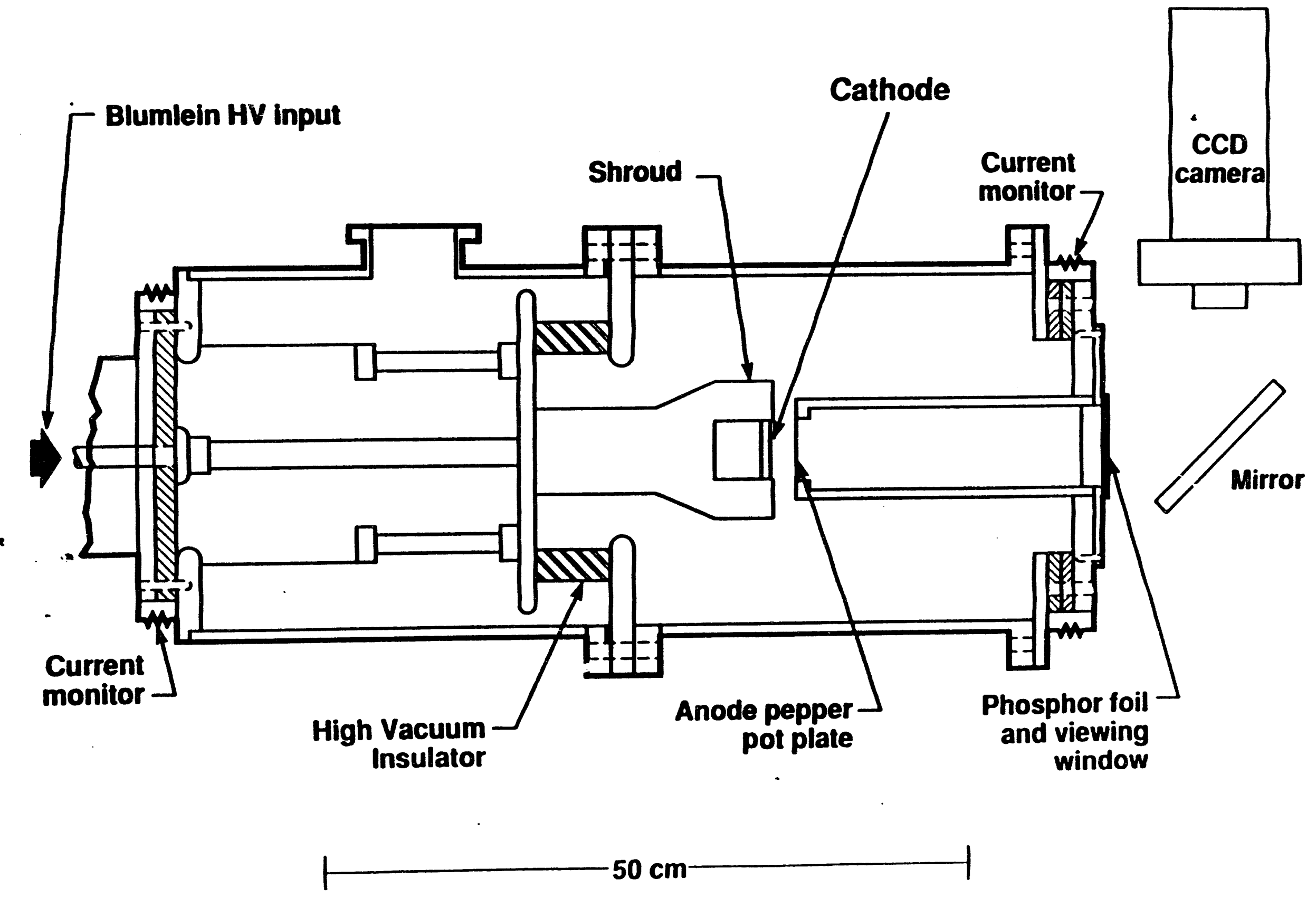




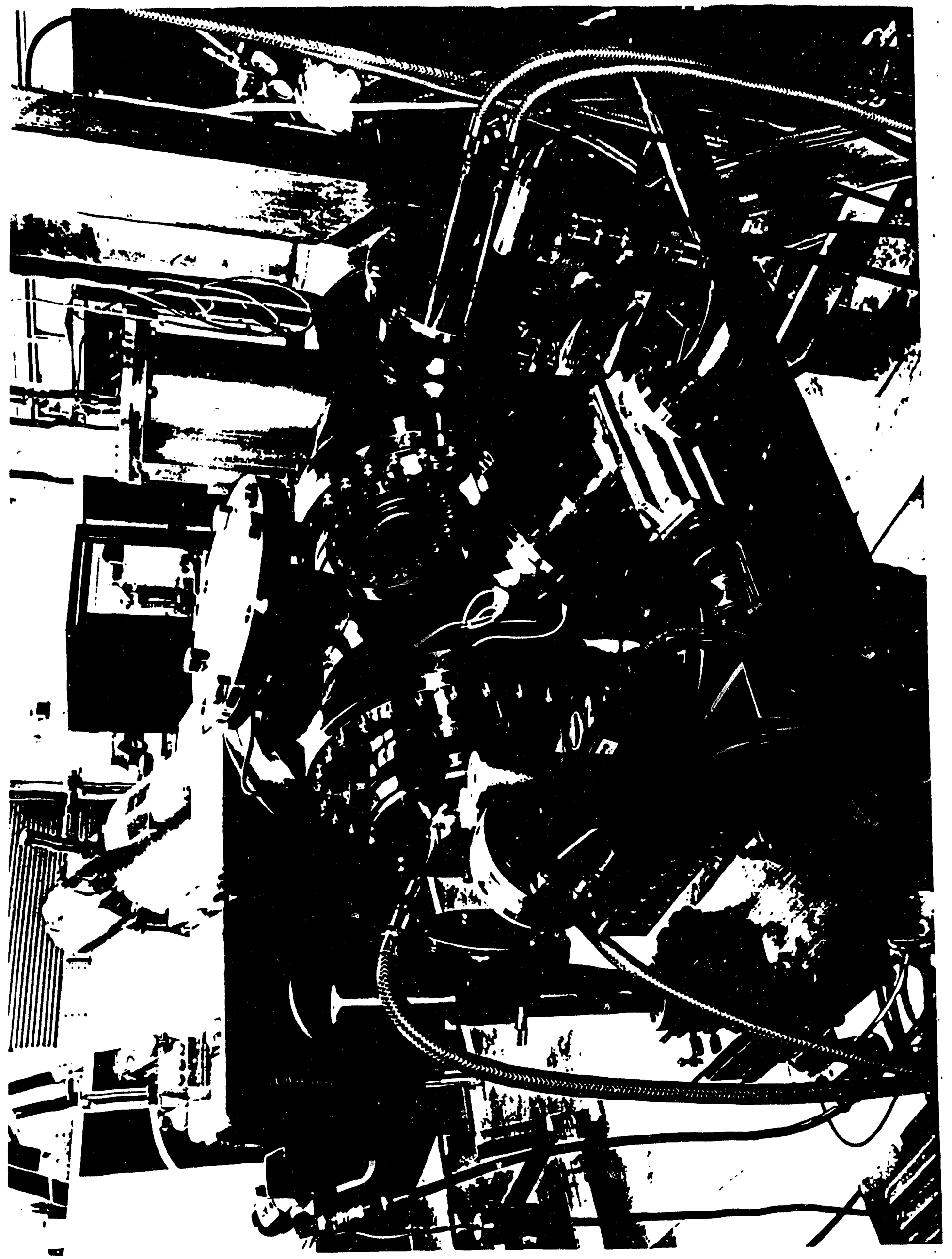




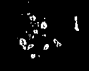

$$
=
$$

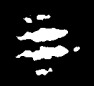

3

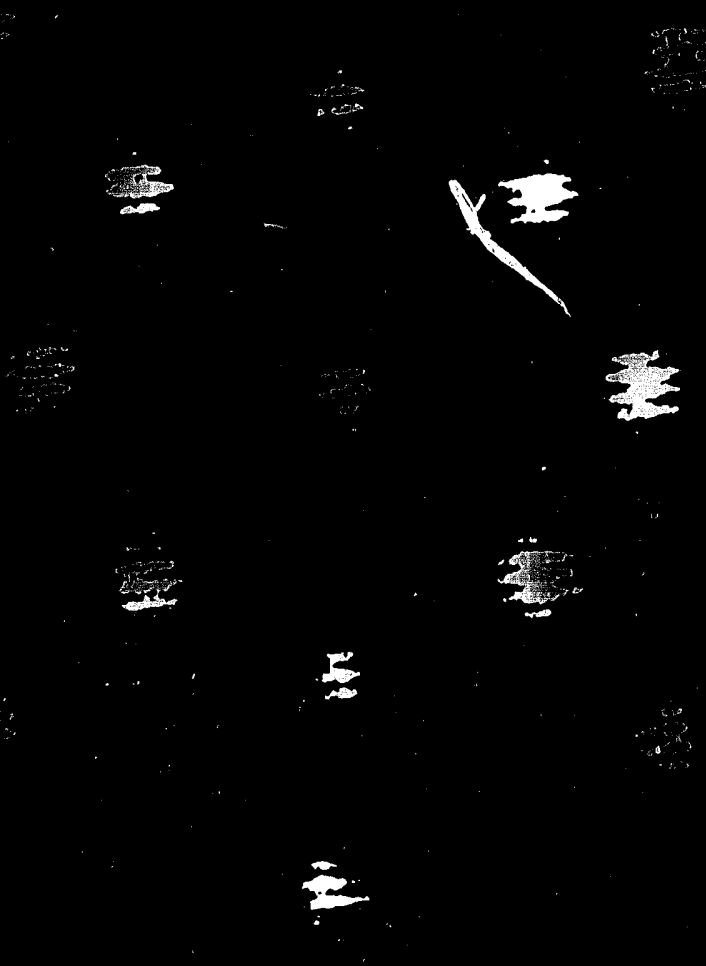

更

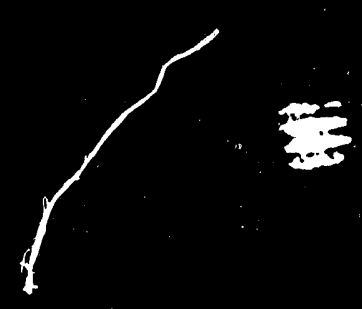




\section{Experimental particulars}

- Cathode preparation

$-3 \mathrm{~cm}$ diameter emission area

- optically polished surface

- Tungsten grid, $0.025 \mathrm{~mm}$ diameter wire, $0.75 \mathrm{~mm}$ on centers

- Inversion pulse

- 2kV, 100 ns pulse width, 20 ns rise-time

- negative screening charge directed toward A-K volume

- Observations

- No degradation after 20,000 pulses

- Discharge occurs between grid and emitter during polarization inversion

- A-K gap is luminous when main high voltage pulse is present

- Gap current is unipolar 


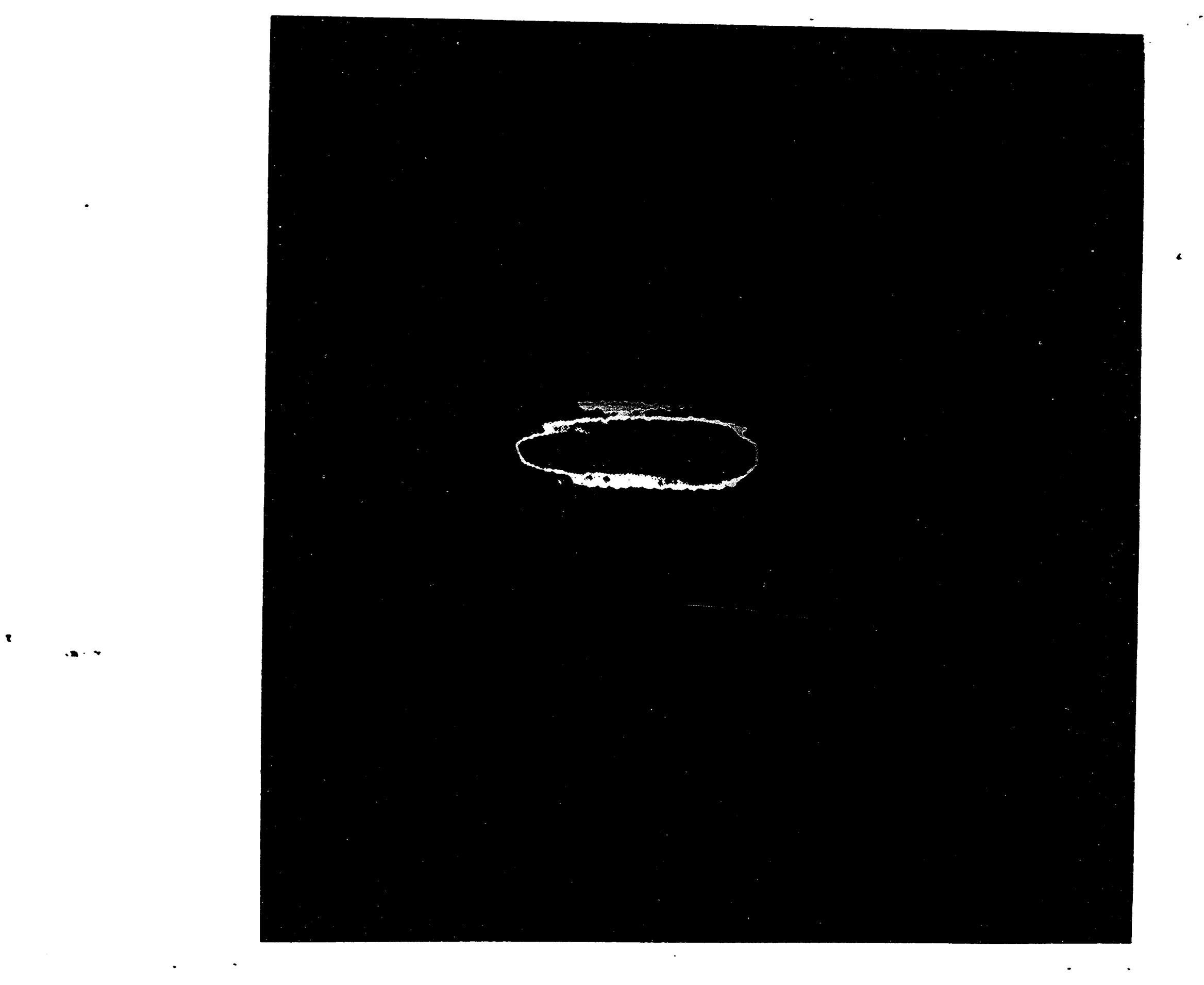



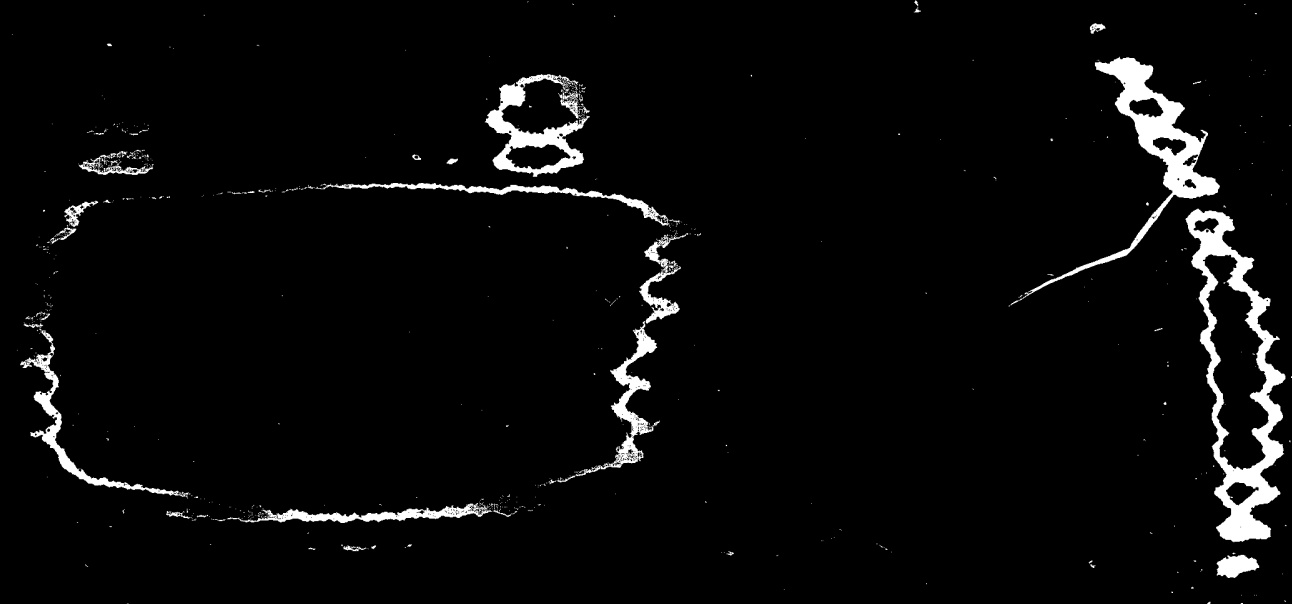

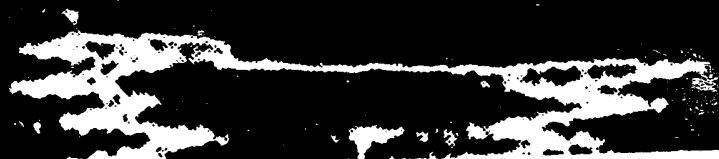




\section{Optimum timing is required between A-K}

pulse and inversion pulse

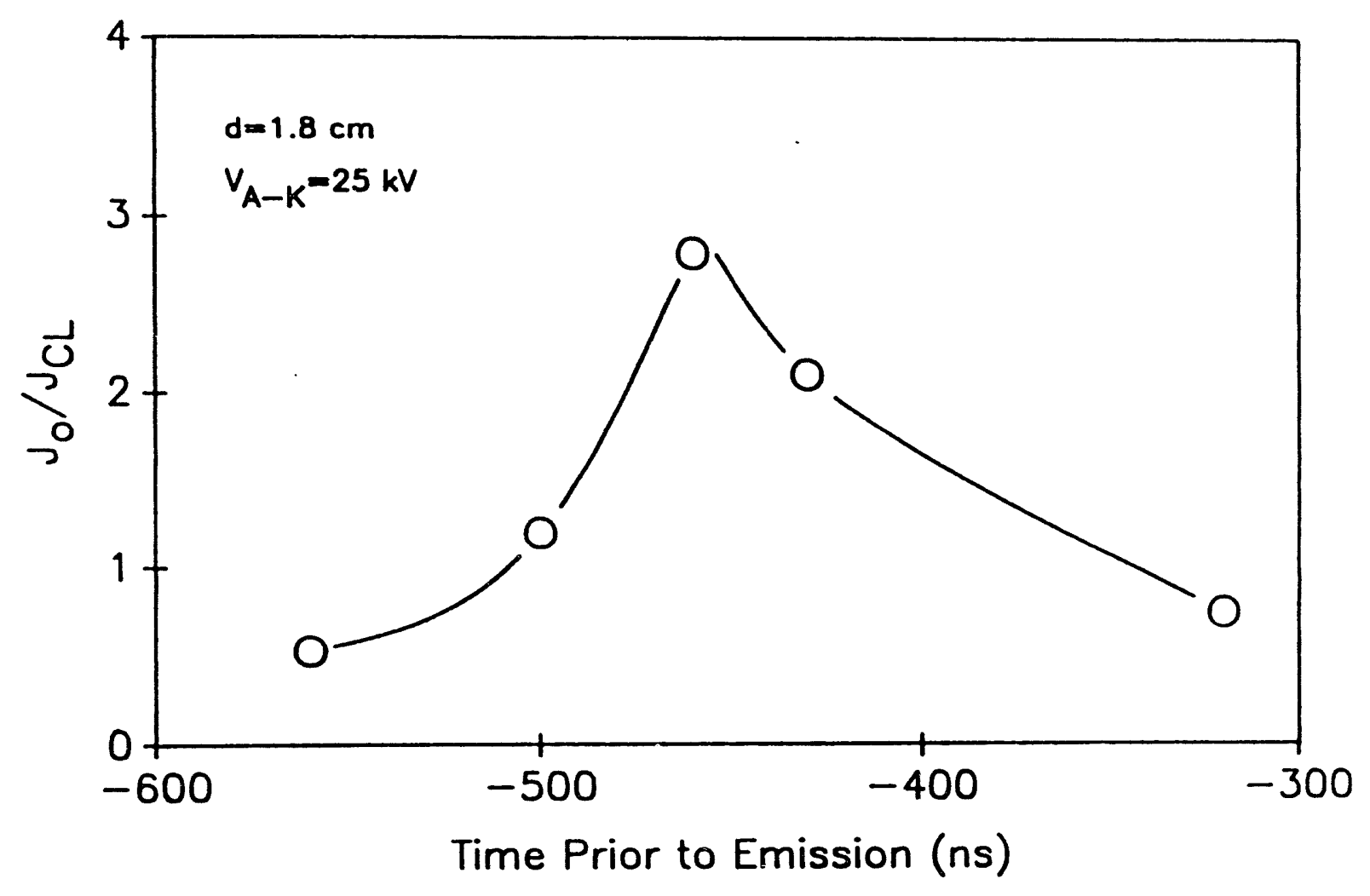

- Implies electron cloud does not instantaneously appear

- Diffusion of electron cloud appears to have a time constant of $100 \mathrm{~ns}$ 


\section{Emitted current exceeds the classical Child-Langmuir}

limit by a factor of 2

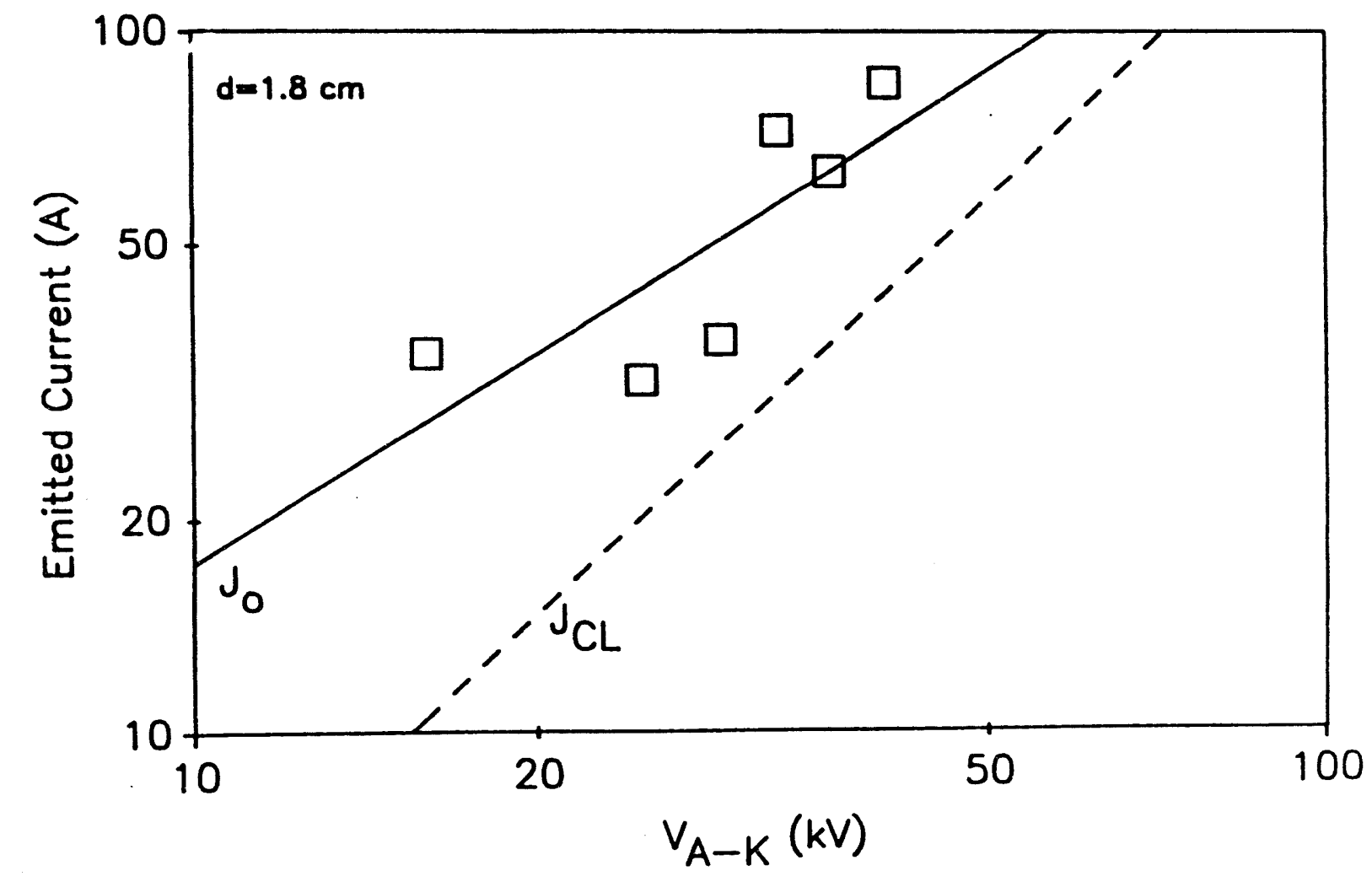




\section{Non-zero initial kinetic energy is believed to be responsible for currents above classical S.C.L.}
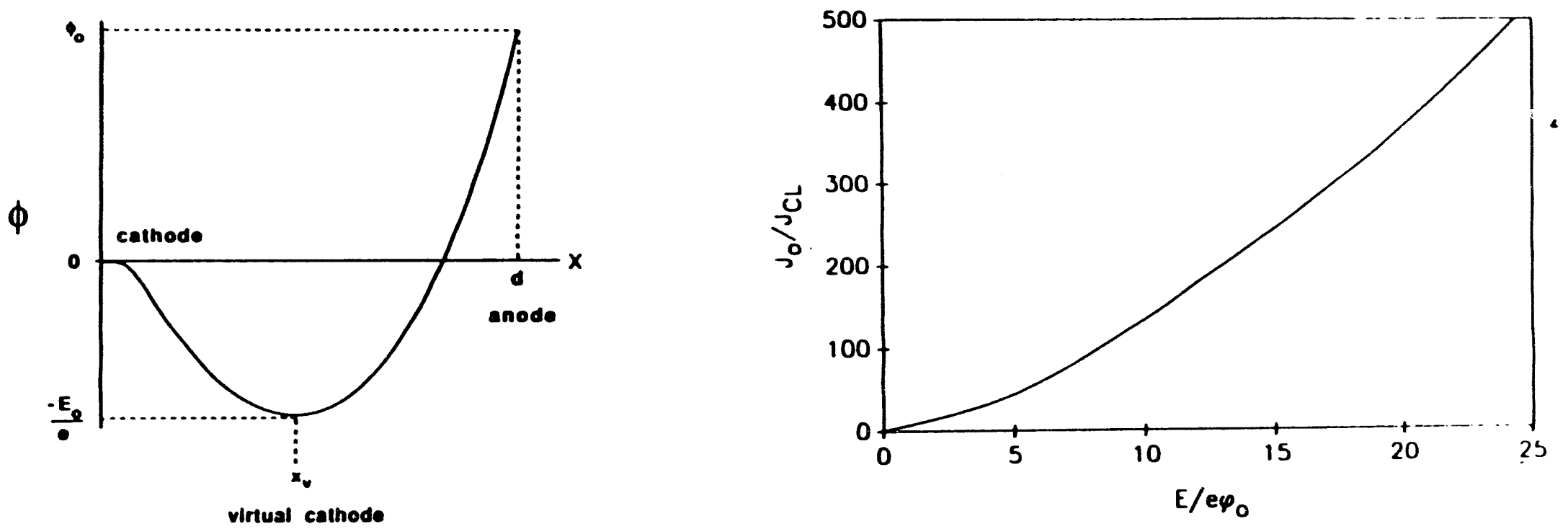

- Non-zero initial energy results in the narrowing of the effective A-K gap and increased effective $A-K$ potential $\left(\phi+\frac{E}{e}\right)$

- Increased currents result

- Our data implies an initial energy of $5 \mathrm{keV}$ 


\section{Brightness measurements}

- Used a 9-hole "x" pattern anode mask

- Varied A-K potential from 11-21 kV; current varied from 0.9-4.7 $\mathrm{J}_{\mathrm{cL}}$

- Mask pattern on phospor severly distorted after $24.5 \mathrm{~cm}$ drift distance

- Image on mask varied from shot-to-shot

- Estimated brightness $\left(J=\frac{1}{\pi^{2} \gamma^{2} \beta^{2} R_{c}{ }^{2} \theta^{2}}\right)$

$$
\begin{aligned}
& <1.7 \mathrm{~J}_{\mathrm{CL}} \sim 10^{9} \mathrm{~A} / \mathrm{m}^{2}-\mathrm{rad}^{2} \\
& \sim 4.7 \mathrm{~J}_{\mathrm{CL}} \sim 5 \times 10^{8} \mathrm{~A} / \mathrm{m}^{2}-\mathrm{rad}^{2}
\end{aligned}
$$




\section{Summary}

- Our initial experiments imply non-zero kinetic energy of the emitted electrons; further study with an electron spectrometer is planned

- We observe that optimum timing is required for peak emission; we will attempt to correlate the effect to late time transverse energy of the emitted beam

- Luminescence is observed on the surface and in the gap volume; we will time correlate this observation to the emitted electrons

- Attempts at a brightness meassrement with a single hole aperature has been unsuccessful; we have installed a multiple hole aperature to observe beam uniformity - we measured a lower bound at $10^{9} \mathrm{~A} / \mathrm{m}^{2}-\mathrm{rad}^{2}$ at reduced currents 

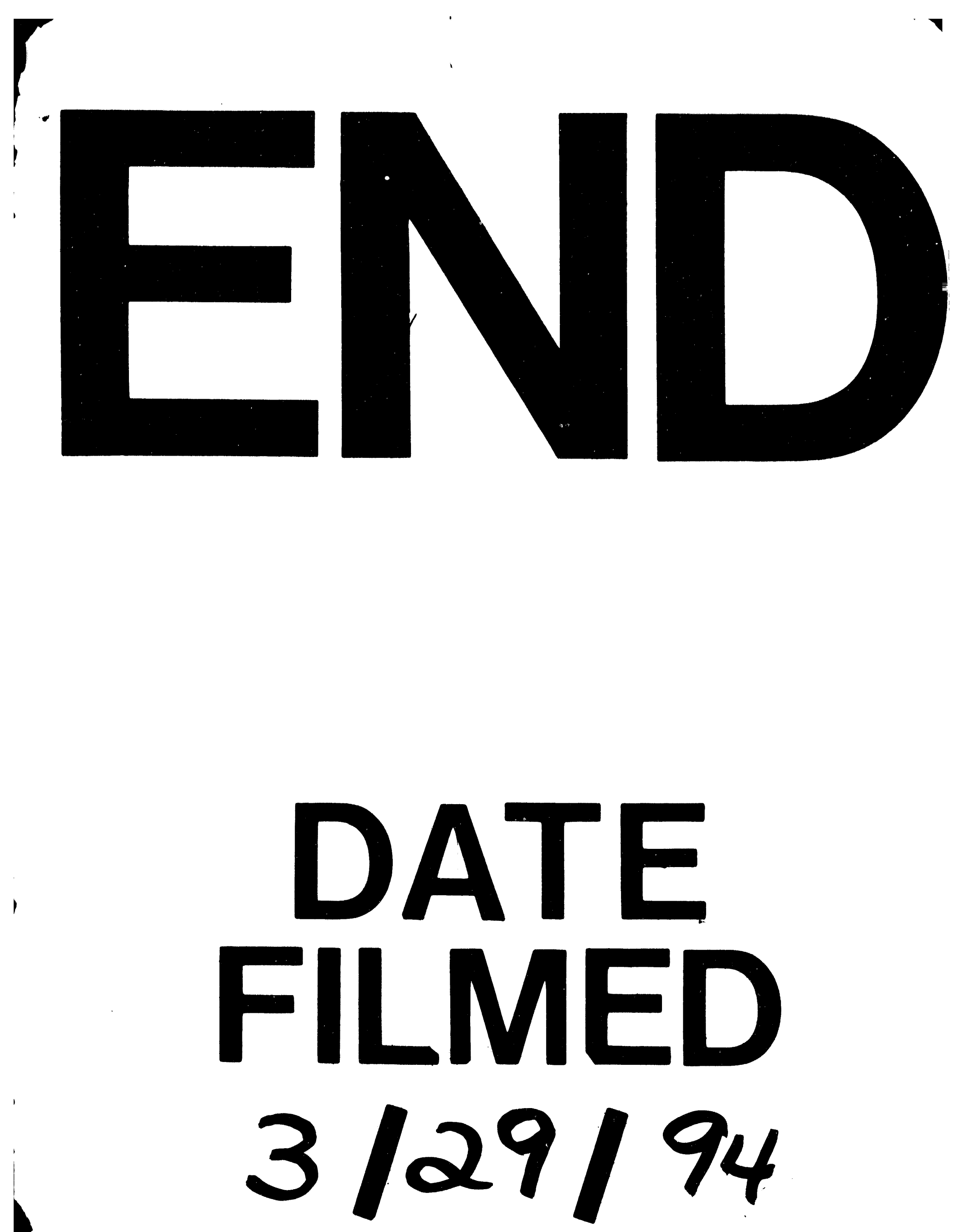